\title{
The study of Priapulus caudatus reveals conserved molecular patterning underlying different gut morphogenesis in the Ecdysozoa
}

José M Martín-Durán ${ }^{*}$ and Andreas Hejnol

\begin{abstract}
Background: The digestive systems of animals can become highly specialized in response to their exploration and occupation of new ecological niches. Although studies on different animals have revealed commonalities in gut formation, the model systems Caenorhabditis elegans and Drosophila melanogaster, which belong to the invertebrate group Ecdysozoa, exhibit remarkable deviations in how their intestines develop. Their morphological and developmental idiosyncrasies have hindered reconstructions of ancestral gut characters for the Ecdysozoa, and limit comparisons with vertebrate models. In this respect, the phylogenetic position, and slow evolving morphological and molecular characters of marine priapulid worms advance them as a key group to decipher evolutionary events that occurred in the lineages leading to C. elegans and D. melanogaster.

Results: In the priapulid Priapulus caudatus, the gut consists of an ectodermal foregut and anus, and a mid region of at least partial endodermal origin. The inner gut develops into a 16-cell primordium devoid of visceral musculature, arranged in three mid tetrads and two posterior duplets. The mouth invaginates ventrally and shifts to a terminal anterior position as the ventral anterior ectoderm differentially proliferates. Contraction of the musculature occurs as the head region retracts into the trunk and resolves the definitive larval body plan. Despite obvious developmental differences with C. elegans and D. melanogaster, the expression in P. caudatus of the gut-related candidate genes NK2.1, foxQ2, FGF8/17/18, GATA456, HNF4, wnt1, and evx demonstrate three distinct evolutionarily conserved molecular profiles that correlate with morphologically identified sub-regions of the gut.

Conclusions: The comparative analysis of priapulid development suggests that a midgut formed by a single endodermal population of vegetal cells, a ventral mouth, and the blastoporal origin of the anus are ancestral features in the Ecdysozoa. Our molecular data on P. caudatus reveal a conserved ecdysozoan gut-patterning program and demonstrates that extreme morphological divergence has not been accompanied by major molecular innovations in transcriptional regulators during digestive system evolution in the Ecdysozoa. Our data help us understand the origins of the ecdysozoan body plan, including those of C. elegans and D. melanogaster, and this is critical for comparisons between these two prominent model systems and their vertebrate counterparts.
\end{abstract}

Keywords: C. elegans, Drosophila, Ecdysozoa, Endoderm, Gut development, Hindgut, Mesoderm, Midgut, Mouth, Priapulid

\footnotetext{
* Correspondence: chema.martin@uib.no

Sars International Centre for Marine Molecular Biology, University of Bergen,

Thormøhlensgate 55, 5008 Bergen, Norway
} 


\section{Background}

A defining character of animals is the need to incorporate other organisms, or their products, for nourishment. Although different strategies have evolved to accomplish this task $[1,2]$, the solution present in almost all metazoans is the development of organs with specialized cell types to ingest and digest food, and absorb the resulting nutrients. The digestive system is thus a central morphological and physiological constituent of metazoans, and, as such, has experienced intense adaptation and diversification, as animals have radiated into different ecological niches and utilized new food sources and predatory strategies [1]. Accordingly, how this variety of digestive systems originated emerges as a key question in the study of animal body plan evolution.

Whereas many early-branching animal lineages, such as Cnidaria (that is, jellyfish, corals), show a sack-like intestine that opens to the exterior through the mouth, most bilaterally symmetrical animals (for example, mammals, flies, and earthworms) exhibit a through gut with two openings, the mouth and the anus, and distinct regions specialized for particular feeding tasks [1]. Pharynxes, jaws, and proboscides to capture and grind food, stomachs and digestive glands to process nutrients, and cloacae to release excretory products are just a few examples of the specializations exhibited by animal digestive systems. Despite this diversity in gut architecture and complexity, the comparative study of different bilaterian animals has revealed commonalities in the early ontogenetic stages of gut formation, and a handful of genes have been related to the specification and initial development of the digestive system [3-6]. The gut usually forms from a population of cells that are localized at one point of the early embryo and that get internalized in a process called gastrulation [7]. These cells, the endoderm (literally, internal skin) of the embryo, form the most medial part of the intestine, which opens into the ectoderm (external skin) through the mouth and the anus. Beyond these broad commonalities, the way in which the gut forms may significantly change as organisms undergo developmental adaption in response to de novo habitat colonization [8-10].

Two extremely specialized modes of gut development are observed in the terrestrial nematode Caenorhabditis elegans and the fruit fly Drosophila melanogaster, the most widely used invertebrate model systems in developmental biology and biomedical research [11-13]. Both the nematode and the fruit fly belong to the Ecdysozoa (molting animals) [14] (Figure 1A), which is one of the three main animal lineages that form the Protostomia, together with the Spiralia and the enigmatic Chaetognatha [15-17]. In C. elegans, the entire tube-like intestine consists of 20 cells; it opens anteriorly through a buccal cavity and a muscular pharynx of less than 100 cells, and
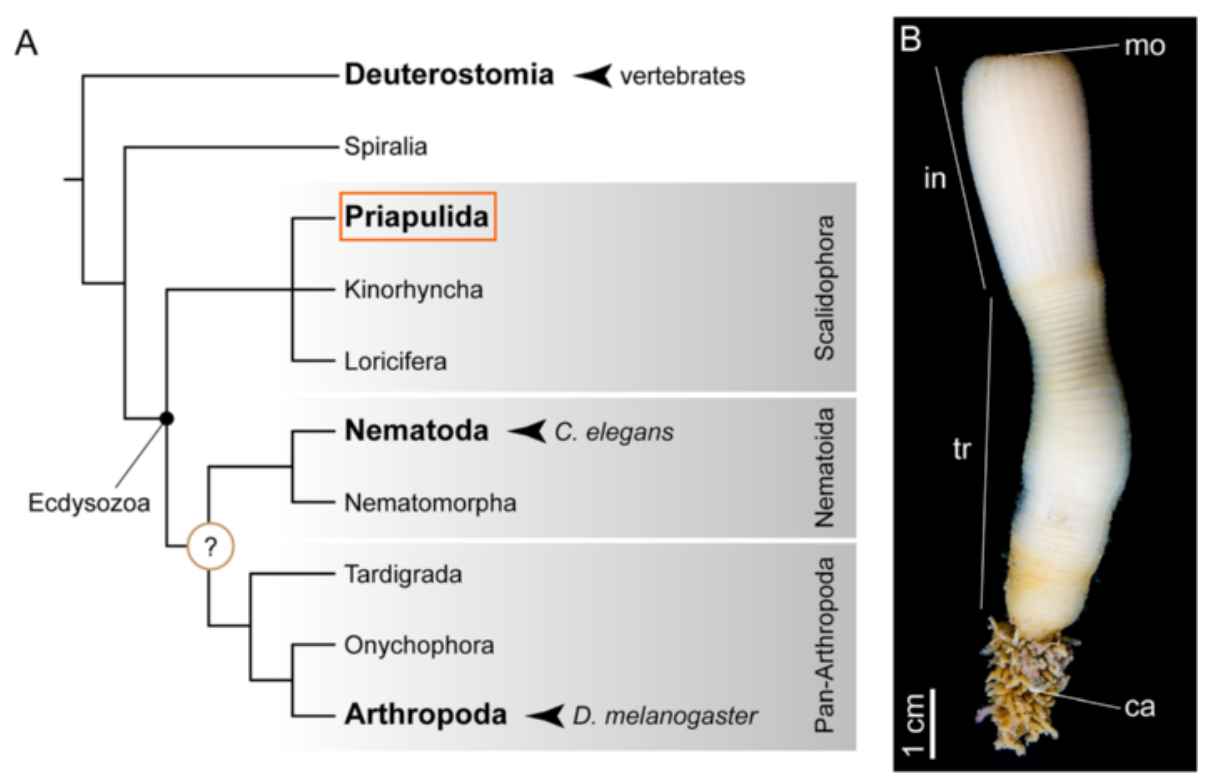

Figure 1 Ecdysozoan model systems and the reconstruction of ancestral characters. (A) The Ecdysozoa (molting animals) comprises three main lineages, namely Scalidophora, Nematoida, and Pan-Arthropoda. C. elegans and D. melanogaster, the two most important invertebrate model systems, belong to Nematoida and Pan-Arthropoda, respectively. The study of a representative of the third main ecdysozoan lineage, the Scalidophora, and in particular of the marine Priapulida, will shed light on ancestral character states present at the base of the Ecdysozoa, and thus on the evolutionary events that occurred in the lineages leading to nematodes and arthropods. Phylogenetic relationships are according to [29]. (B) Adult priapulid of the species Priapulus caudatus. Priapulids are sausage-shaped annulated worms, with an anterior introvert (in), a terminal mouth (mo), a trunk (tr), and a posterior caudal appendage (ca). 
posteriorly through an ectodermal hindgut of 11 cells [18-20]. The 20 intestinal cells are clonal, and originate from a single founder cell, the E blastomere, at the eight-cell embryo [21-24]. The E cell first divides once on the surface of the embryo, and the resulting daughter cells migrate into the embryo during gastrulation. Three rounds of cell division generate a 16-cell intestinal primordium, in which cell differentiation and lumen formation take place [18]. C. elegans is thus the archetypal example of an animal with a highly stereotypic determinative development, reduced number of cells, and fast life cycle [21]. Differing from C. elegans, the development of $D$. melanogaster, as also observed in many other arthropods, is strongly adapted to terrestrial environments and yolky eggs [10]. The more complex digestive system of the fly D. melanogaster is made of thousands of cells, and is divided into an ectodermal foregut (mouth, esophagus, crop, and proventriculus), an endodermal midgut subdivided into at least six physiological regions, and an ectodermal hindgut [25]. Strikingly different from most animals, the endoderm is specified in two different regions of the embryo before gastrulation, namely the anterior and the posterior midgut primordia [26]. These two cell populations undergo an epithelial to mesenchymal transition, and ingress inside the embryo, which is filled by yolk. The foregut and hindgut, which surround the anterior and posterior midgut primordia respectively, invaginate after the mesenchymal endodermal cells. The two endodermal populations then migrate through the embryo to eventually meet at the middle, and re-epithelialize to define the digestive tract [27], in a process tightly coupled with the development of the visceral mesoderm [28]. Although $C$. elegans and $D$. melanogaster are by far the two best-studied ecdysozoans, their highly peculiar and adaptive modes of development hinder the reconstruction of ancestral and derived characters for nematodes and arthropods (Figure 1A). Therefore, alternative taxa are needed to understand the evolutionary origins of the development of the digestive tract in these two model systems and in the Ecdysozoa as a whole, which is ultimately essential for the interpretation and translation of the research conducted on C. elegans and $D$. melanogaster to model vertebrate systems, such as the frog, fish and mouse.

Most recent phylogenies place the exclusively marine priapulid worms (Priapulida), and the related taxa kinorhynchs and (likely) loriciferans, as the earliest branching ecdysozoan lineage (Scalidophora), and thus the sister group to the remaining ecdysozoans, including nematodes and arthropods $[15,17,29]$ (Figure 1A). The extant Priapulida comprise only 19 described species $[2,30]$, but were among the most abundant and widespread animals in the Early Cambrian [31]. The oldest trace fossils from the beginning of the Cambrian (Treptichnus pedum) resemble burrowing priapulids, or morphologically very similar animals [32]. Priapulids, commonly referred to as penis worms, are large sized $(0.5$ to $20 \mathrm{~cm})$, mud-dwelling or interstitial annulated worms, with an anterior proboscis (or introvert), and a terminal mouth [2,33] (Figure 1B). Reports on their embryonic development are scarce and mostly focused on the early stages of development of the species Priapulus caudatus Lamarck 1816 [34,35]. $P$. caudatus reproduces by external fertilization, and the small embryos undergo holoblastic radial cleavage, gastrulation by invagination and epiboly [35], and deuterostomic formation of the mouth [34], which are all considered to be plesiomorphic features in the Ecdysozoa $[34,36]$. This combination of characters, together with their slow rate of molecular evolution [37], render the Priapulida, and in particular the representative species $P$. caudatus, as the key conservatively evolving ecdysozoan group to compare with nematodes and arthropods, and to thereby infer ancestral characters for these species-rich lineages of animals.

In the present study, our aim was to characterize the formation of the gut in P. caudatus and then, by comparing our data with the knowledge on C. elegans, $D$. melanogaster, and other bilaterians, to decipher the evolutionary events that occurred after cladogenesis of the nematode and arthropod lineages. Principally, we focused on the morphological development of the endoderm into the definitive intestine, as well as on how the mesoderm segregates from the endoderm and its putative influence on the formation of the gut. We then analyzed mouth and head development, as well as the molecular regionalization of the definitive digestive system, by studying the expression of the mouth markers $N K 2.1$, foxQ2, and FGF8/17/18; the midgut markers GATA456 and hepatocyte nuclear factor 4 (HNF4); and the hindgut markers wnt1 and evenskipped (evx). Our data shed light on the origins and evolution of the digestive tracts of C. elegans, D. melanogaster, and the Ecdysozoa in general. Importantly, our data demonstrate that a conserved molecular patterning system underlies the great variability of ontogenetic modes and architectures observed in the digestive systems of ecdysozoans.

\section{Results}

\section{Gut formation in P. caudatus}

Gastrulation is usually the first morphogenetic step in the formation of the digestive tract in metazoans $[7,38]$. During this event, the endomesodermal cells, which will form the digestive system and mesodermal derivatives, internalize and segregate from the external ectoderm. In $P$. caudatus, gastrulation occurs at the vegetal pole [35], and after endomesoderm ingression, the embryo shows an obliterated archenteron, and a narrowed 
blastopore that corresponds to the future anal opening of the digestive tract [34]. At this stage, between days 4 and 5 of development, the endomesoderm exhibits a parenchymatic appearance (Figure 2A), without any obvious morphological differences between the future endodermal cells and the mesoderm. The mouth appears ventrally in the animal hemisphere [34], as an ectodermal invagination of a few cells (Figure 2A, A'), and a subequatorial ectodermal groove marks the division of the body into an anterior/animal introvert and a posterior/vegetal trunk (introvertula stage).

After 6 days of embryogenesis, the basic organization of the priapulid gut emerges (Figure 2B, B', Additional file 1: Figure S1A). The ectodermal mouth consists now of several tens of smaller ectodermal cells, and occupies an anterior terminal position, as observed in the adult.

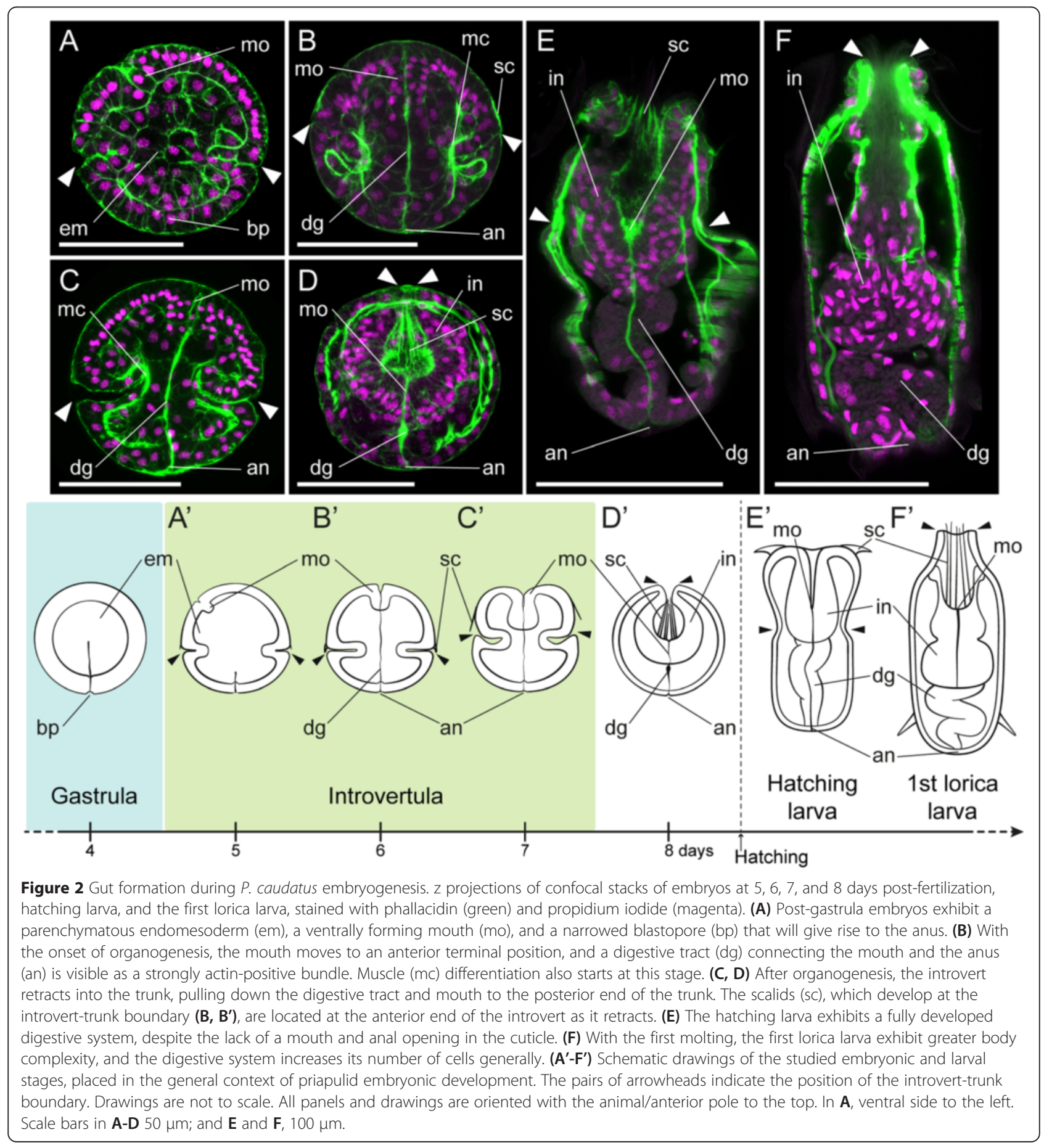


The endomesoderm is clearly segregated into endoderm and mesoderm: the gut appears as a straight tract connecting the anterior mouth to the posterior anus and is observed as a strongly actin-positive bundle, while the first signs of muscle differentiation become visible in the trunk and introvert (see also Figure 3F). At this stage, and based on whether cells belong to the external mono-layered ectoderm or not, the gut in P. caudatus consists of an anterior ectodermal mouth (foregut), an internal tract of at least partial endodermal origin, and a posterior ectodermal opening (anus) (Additional file 1: Figure S1B-E). The internal portion of the alimentary canal seems to be made of a limited and constant number of cells, being formed by three tetrads of cells and two pairs of cells serially arranged from anterior to posterior (Additional file 2: Video S1).

After the formation of the gut anlage, about days 7 to 8 of development, the introvert retracts and becomes sheathed in the trunk (Figure 2C,D,C', $\mathrm{D}^{\prime}$ ). This is a key event during priapulid embryogenesis, as it results in the emergence of the larval/adult body plan [39]. Strikingly, when the introvert develops it is unfolded (Additional file 3: Figure S2). The animal-most ectoderm corresponds to the inner epidermis of the introvert, often called the oral or buccal cavity. At the most anterior region of the oral cavity, which in the embryo corresponds to the anterior region of the introvert-trunk boundary, the scalids (feeding teeth) develop ([34] and Figure 2B). The ectodermal indentation of the introvert-trunk boundary thus corresponds to the external epidermis of the introvert, the neck region (transition from the introvert and trunk), and the anterior epidermis of the trunk. During retraction, the initially extended inner gut (Figure 2C) is pulled down to the posterior end of the embryo (Figure 2D), as the introvert is incorporated inside the trunk, which also extends anteriorly during this process. As a result, the foregut, located at first at the anterior pole of the embryo, is internalized inside the embryo, and adopts a posterior position within the now folded introvert (Figure 2D, D'; Additional file 3: Figure S2). The posterior region of the embryo, and thus the anus, is not significantly affected by these major morphological rearrangements (Figure 2C,D,C',D'). Additionally, introvert retraction is required for embryo hatching. The protrusion of the introvert eventually opens the hatching cap [35], allowing the hatching larva to escape.

A previous study of the external morphology of the hatching larva of $P$. caudatus reported the lack of mouth and anal openings in the larval cuticle [39]. Despite this absence, the hatching larva does show a fully developed digestive tract (Figure 2E,E'), similar to the one observed during embryonic development. No additional glands or attached organs are observed in close contact with the tube-like intestine. The first molting event, which results in the formation of the first lorica larva [39], involves a significant change in larval morphology and cell number (Figure 2F). The introvert and trunk grow in size and complexity, the internal portion of the alimentary canal is now formed by a greater number of cells, and the mouth and anal openings are present in the cuticle [39]. This observation suggests that the attainment of the mature digestive tract, as observed in the adult, is accomplished through successive molting events.

\section{Mesoderm development in $P$. caudatus}

Segregation of endodermal and mesodermal precursors from a common endomesodermal germ layer is the first step in the development of their respective cell types and organs. During and immediately after gastrulation in $P$. caudatus, the endomesoderm shows no overt signs of segregation between endodermal and mesodermal populations (Figure 2A). However, there is expression of the endodermal marker fox $A$ in the most animally located endomesodermal cells [34]. To identify the mesodermal precursors at this developmental stage, we analyzed the expression of the evolutionarily conserved mesodermal marker twist (twi) $[40,41]$. During gastrulation, twi transcripts are detected in the blastopore and the most vegetal endomesodermal cells, as well as in two lateral rows of internal cells (Figure 3A,B). Endoderm and mesoderm are thus likely distinct cellular populations already during gastrulation. As organogenesis proceeds through the introvertula stage, twi expression is detected in two broad rings of cells around the introvert and trunk (Figure 3C,D), which might correspond to the developing musculature (compare with phallacidin-positive muscles of the trunk and introvert in Figure 3F,G).

Differentiation of the mesoderm, and in particular of the surrounding visceral musculature, is essential for proper endoderm development in model organisms such as $D$. melanogaster and vertebrate embryos $[4,28]$. In $P$. caudatus, the organization of a recognizable gut tract by day 6 of development occurs simultaneously with the onset of muscle differentiation (Figure 3E,F). The first signs of this event are observed at the time of mouth formation, with the appearance of actin-positive circular fibers around the introvert-trunk boundary (Figure 3E). At the introvertula stage (Figure 3F), the body-wall musculature is obvious, with the development of circular muscles, mostly concentrated at the trunk level, and longitudinal muscles that connect the developing introvert with the trunk (inset Figure 3F). Before the retraction of the introvert (Figure 3G), the musculature appears further developed, in particular there are more muscle fibers at the introvert level. Introvert retraction, and thus the positioning of the digestive system in its final location, might be a muscle-controlled process, as is also the 


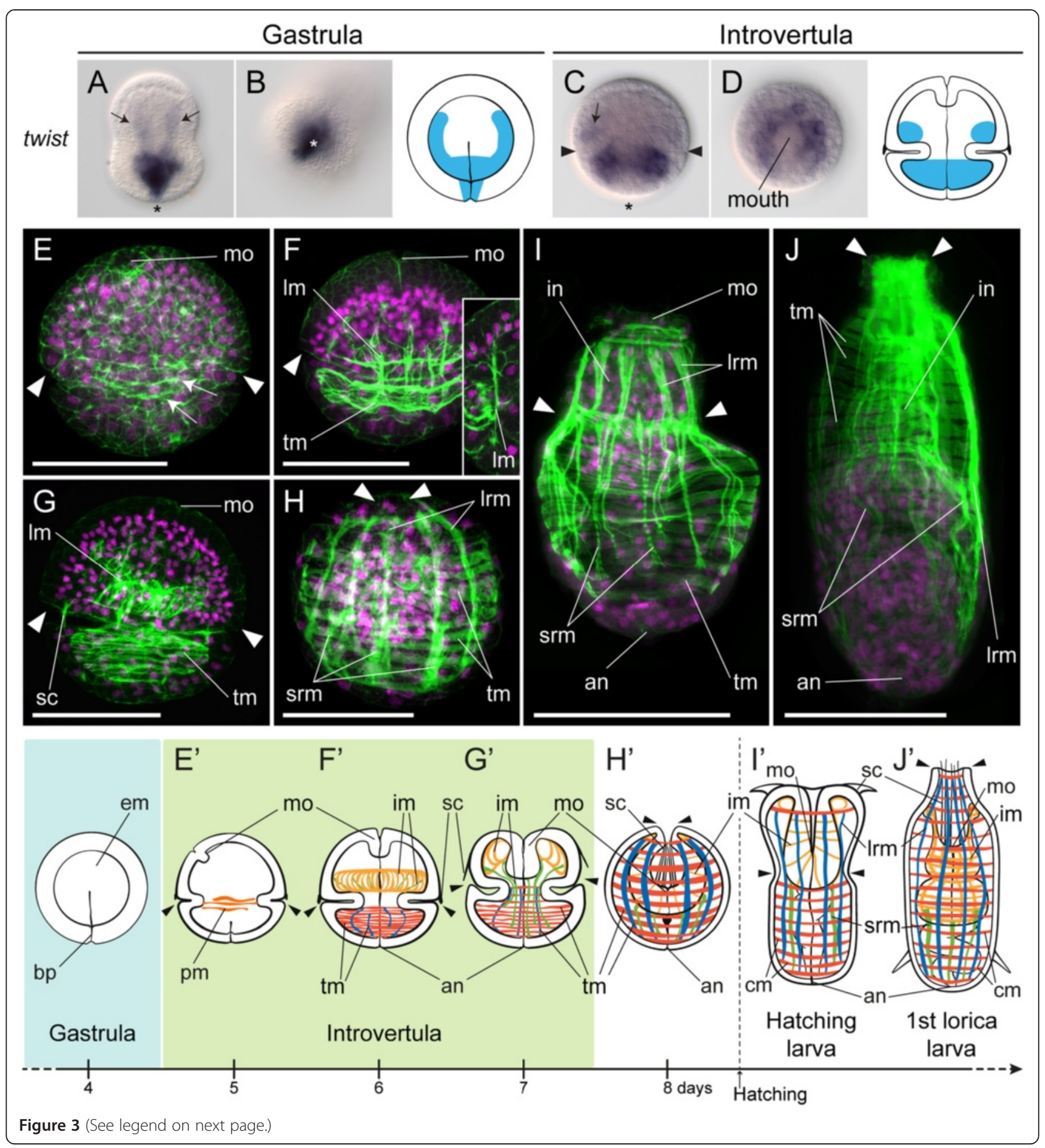


(See figure on previous page.)

Figure 3 Mesoderm specification and myogenesis in Priapulus caudatus. (A-D) Whole-mount in situ hybridization of twist. twi is expressed in the most vegetal endomesodermal cells, and in two lateral bands of the gastrula (black arrows in $\mathbf{A}$ ) and later in the developing musculature of the introvert (black arrow in $\mathbf{C}$ ) and trunk. In (A-C) the asterisk indicates the blastopore/anus. Drawings depict the expression domains. The slight elongation of embryos might be an artifact of fixation. (E, F) z projections of confocal stacks of embryos at 5, 6, 7, and 8 days post-fertilization, hatching larva, and the first lorica larva, stained with phallacidin (green) and propidium iodide (magenta). (E) Muscle fibers appear as actin-positive bundles around the equator of the embryo (white arrows). (F) Subsequently, the trunk musculature and longitudinal muscles (Im) (inset) become visible. (G) Before introvert retraction, the musculature appears more developed. (H) Introvert retraction extends the circular and longitudinal musculature of the trunk, while short retractor muscles attach the introvert to the trunk. (I) The hatching larva exhibits a musculature similar to that of the late embryo, while $(\boldsymbol{J})$ the first molt involves an increase in general complexity. (E'-J') Schematic drawings depicting the basic muscular patterns. A, C, E-J, lateral views; B, vegetal view; and D, anterior view. All panels and drawings are oriented with the animal/anterior pole to the top. In $\mathbf{E}$, ventral side to the left. The pairs of arrowheads in $\mathbf{C}$ and $\mathbf{E}-\mathbf{J}$ ' indicate the position of the introvert-trunk boundary. Drawings are not to scale. Scale bars in E-H, 50 Hm; and I and J, 100 Mm. an, anus; bp, blastopore; cm, circular muscles; em, endomesoderm; im, Introvert musculature; Irm, long retractor muscles; mo, mouth; pm, primary muscles; sc, scalids; srm, short retractor muscles; tm, trunk musculature.

case during the protrusion and retraction of the adult introvert. As a consequence of the retraction of the introvert, the trunk musculature extends, and the circular packs of musculature and long retractor muscles become evident (Figure 3H). There are also shorter longitudinal retractor muscles connecting the posterior region of the introvert to the trunk. As observed with the digestive system, the musculature pattern observed in late embryos is conserved in the hatching larva (Figure 3I), and the number of muscle fibers increases after the first molting event (Figure 3J). Despite the fact that the adult priapulid gut is surrounded by a layer of longitudinal muscles that directly attaches to the basal lamina of the endoderm, our investigations point towards the absence of this musculature in priapulid embryos and first larval stages (see Figure 2E,F). The visceral musculature may thus develop in subsequent larval stages, in connection with the appearance of feeding behaviors [39] and a functional digestive system.

\section{Cell proliferation and cell migration during mouth development}

An anterior terminal position of the mouth has been proposed to be a plesiomorphic character in the Ecdysozoa $[29,42]$. To better understand the mechanisms governing the movement of the priapulid mouth from its ventral site of emergence to the most anterior tip of the body, we incubated embryos with the thymidine analog EdU to identify and track cells in the S-phase of the cell cycle. We treated embryos before mouth invagination (day 3.5 of development), at the point of ventral invagination (day 4.5), and when the mouth adopts an anterior terminal position (day 5.5), and fixed the treated embryos after 6, 12, and 24 hours (Figure 4A). With this set-up, we were able to detect active cycling cells at these points of development, and trace their position and the position of their daughter cells over the 24 hours following each respective labeling pulse.
Before mouth invagination, cell proliferation is mostly concentrated in the animal hemisphere of the embryo (Figure 4B), in the region that will form the introvert. This observation explains the greater number of nuclei observed in the introvert region using standard nuclear staining methods (for example, compare introvert and trunk regions in Figure 2B,C), and this region corresponds to the area of brain and proboscis formation. Localization of EdU-positive cells at 12 and 24 hours after the initial pulse demonstrated that labeled cells remained at the introvert region (Figure 4C,D), and that the mouth is formed by cells that originate in the animal hemisphere (inset in Figure 4D). Once the mouth invaginates on the ventral side of the embryo (Figure 4E, and inset), proliferation appears mostly concentrated on one side of the introvert, in a three- to four-cell-wide stripe that spans from the base of the introvert to almost the most anterior tip of the embryo. Individual proliferative cells are also observed in different parts of the introvert and trunk. Labeling for EdU-positive cells, together with cells expressing the oral marker foxA [34], showed that these populations are co-localized (Figure 4F, inset; Additional file 4: Figure S3), and indicates that the asymmetric proliferation observed in the introvert at this stage occurs ventrally, at the region of mouth formation and nervous system development [34]. At this stage, nuclei distribute more or less equally throughout the introvert ectoderm, except around the mouth and in the ventral midline where EdU-positive cells occur (Additional file 4: Figure S3), and ectodermal cells exhibit roughly the same size (see introvert region in Additional file 2: Video S1). Finally, cell proliferation decreases with the establishment of the basic body plan in the priapulid embryo after days 5.5 to 6 of development (Figure 4H-J), with only individual EdU-positive cells being observed in the introvert and trunk region after this time. Altogether, these results indicate that asymmetric cell proliferation is likely to be an important factor in the migration of the mouth from a ventral to an anterior terminal position, although they do 

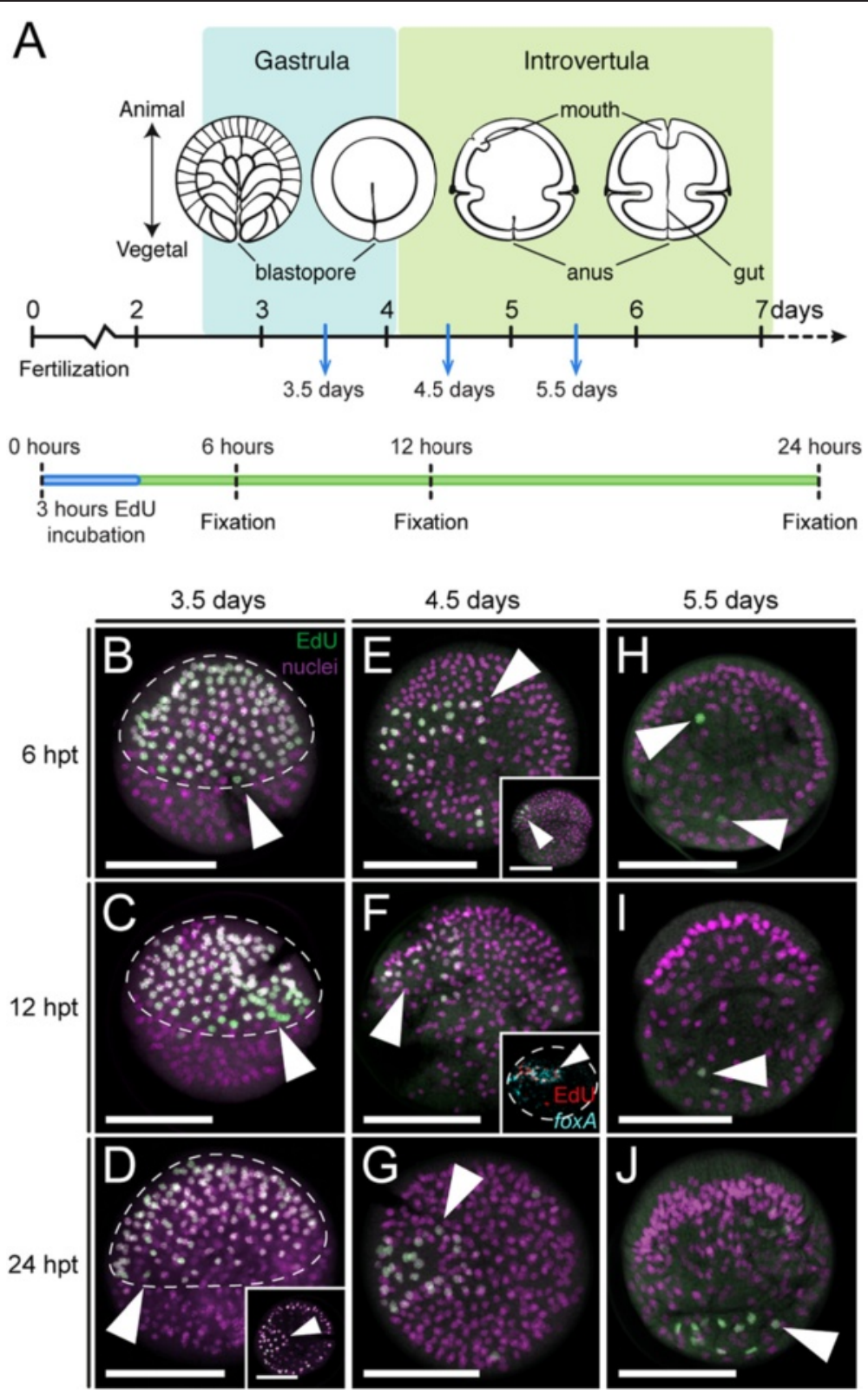

Figure 4 Cell proliferation during mouth development in Priapulus caudatus. (A) Schematic summary of the experimental setup to identify proliferative cells (by means of EdU incorporation) after 3.5, 4.5, and 5.5 days of development, and their position 6, 12, and 24 hours after the EdU pulse. Drawings are not to scale. (B-J) z projections of confocal stacks of embryos labeled for EdU-positive cells (green) and nuclei (magenta). (B-D) After gastrulation, cell proliferation is mostly concentrated in the animal hemisphere (white arrowheads, encircled by the dashed line), where the introvert and mouth (inset in D, white arrowhead) forms. (E-G) With the appearance of the ventral invagination that forms the mouth at 4.5 days of development, proliferation in the introvert becomes asymmetric (white arrowheads), on the side of mouth development, as observed by the co-localization of proliferative cells and cells expressing the mouth marker foxA (inset in $\mathbf{F}$, white arrowhead; dashed line outlines the embryo). (H-J) Beyond 5.5 days of development, after mouth migration and the formation of the digestive tract, proliferative cells appear scattered throughout the introvert and trunk of the embryo (white arrowheads). In $\mathbf{B}-\mathbf{D}, \mathbf{F}, \mathbf{H}-\mathbf{J}$, and inset in $\mathbf{E}$, lateral view; and in $\mathbf{E}, \mathbf{G}$, inset in $\mathbf{D}$ and $\mathbf{F}$, top view. In $\mathbf{D}-\mathbf{J}$, ventral to the left. Scale bars, 50 m. hpt, hours post-treatment.

not rule out that other factors also contribute to a certain extent. Additionally, the similar distribution of labeled cells at different time-points after a common EdU pulse suggests that cell migration is not a major force driving morphogenesis during $P$. caudatus development, as is also observed in the nematode C. elegans [21].

\section{Anteroposterior patterning of the digestive tract of}

\section{P. caudatus}

To characterize in greater detail the specification and formation of the different gut regions, we identified and studied the expression patterns of the anterior/foregut markers NK2.1, foxQ2, and FGF8/17/18; the midgut 
markers GATA456 and HNF4; and the posterior/hindgut markers wnt1 and evx (Figure 5). These markers complement our previous work describing the foregut markers foxA, goosecoid (gsc), and orthodenticle (otx), and hindgut markers brachyury (bra) and caudal (cdx) [34].

The oral ectoderm marker NK2.1 [43] is expressed on one side of the gastrula, separate from the blastopore (Figure 5A,B). At the introvertula stage, NK2.1 is expressed in the most apical region of the introvert, where the mouth is located (Figure 5C,D). foxQ2 is a conserved marker of apical neural ectoderm [44,45], and in C. elegans and D. melanogaster it is also expressed in the foregut [46,47]. During gastrulation, foxQ2 is expressed in the animal-most ectoderm, lateral ectoderm, and weakly in the ectoderm around the blastopore (Figure 5E,F). With the formation of the basic body plan at the introvertula stage, foxQ2 becomes expressed around the mouth and on one side of the introvert, presumably the ventral side which is also the case for the neural marker otx [34]. Finally, FGF8/17/18 shows conserved expression at the mouth region in many studied bilaterians $[48,49]$, and is detected in the animal hemisphere during gastrulation in P. caudatus (Figure 5I,J). At the introvertula stage, FGF8/17/18 is expressed in the mouth and anus, as well as in six clusters of cells in the introvert, distributed in two bilaterally symmetrical rows of three clusters each (Figure 5K,L).

Orthologs of the GATA456 subfamily and HNF4 are evolutionarily conserved markers of the developing midgut [5]. Neither marker was detected at the blastula stage in P. caudatus (Figure 5M,N,Q,R), and their expression only became evident at the introvertula stage, in the inner cells right below the mouth, and thus presumably in the developing midgut (Figure 5O,P,S,T).

Finally, wnt1 is a conserved marker of posterior regions across the Bilateria [50]. During gastrulation, wnt1 is expressed vegetally, around the blastopore (Figure 5U,V), and this expression pattern remains at the introvertula stage, when wnt1 is detected in the posterior tip of the trunk, and anus (Figure 5W,X). The homeobox-containing gene $e v x$ has been shown to play a conserved role in patterning the posterior regions of bilaterian embryos [51,52]. At the gastrula stage, evx is expressed broadly at the vegetal pole (Figure 5Y,Z), and as observed with wnt1, its expression becomes reduced to the posterior end of the trunk and anus at the introvertula stage (Figure 5AA,AB).

\section{Discussion}

\section{Gut development in $P$. caudatus, and the ancestral state} for the Ecdysozoa

The most medial part of the digestive system usually originates from the endoderm, one of the two germ layers internalized during gastrulation in the Bilateria. In the Ecdysozoa, a vast variety of ontogenetic programs lead to the specification of the endoderm and its differentiation into a functional gut, mostly influenced by the particular ecological and developmental adaptations of each organism. The nematode $C$. elegans generates its whole midgut from the single E cell [21-24], located on the ventroposterior surface of the embryo (vegetal hemisphere) in the eight-cell-stage embryo (Figure 6A). The formation of the intestine from an early-specified founder cell seems to be common to most nematode lineages [53-57], and thus is likely the ancestral condition for this group. Nevertheless, nematomorphs, the sister group to nematodes [15], generate the endoderm from a vegetal population of blastomeres internalized during gastrulation [58,59]. Differing from nematodes and nematomorphs, the fruit fly $D$. melanogaster forms the midgut from two separate populations of endodermal cells located at the anterior and posterior pole of the embryo, respectively [26] (Figure 6B). This situation is observed in all winged insects (Pterygota) $[60,61]$ but, in general, most other panarthropod embryos, such as those of myriapods, chelicerates, and onychophorans, form the endodermal cells at a defined point of the blastoderm [10,62-67]. These cells migrate over the yolk mass, and often phagocyte it, to eventually form the midgut. As an exception, crustaceans that develop via a hollow, radial blastula specify the endoderm from a small set of vegetal cells, sometimes even from just one cell $[10,68-70]$. Lastly, in the tardigrade Thulinius stephaniae, the intestine seems to originate from four founder blastomeres of different genealogical origins that are internalized after the primordial germ cells at the anterior pole [71]. Our data on the priapulid P. caudatus, a representative of the Scalidophora, show that its most medial region of the intestine likely forms from a single population of foxA-positive [34] endodermal cells that are internalized during gastrulation, and which occupy an anterior/animal position within the endomesoderm once gastrulation is completed (Figure 6C). The cell movements during gastrulation [35] suggest that these endodermal precursors are the first cells to internalize, and thus occupy the most vegetal region of the priapulid blastula. Nevertheless, detailed cell lineage studies and/or gene expression data at this developmental stage are required to confirm this hypothesis, and also, importantly, to address whether there is an additional contribution of midgut cells from the invaginating foregut ectoderm. Considering that holoblastic radial cleavage is plesiomorphic in the Ecdysozoa [36], and given the diversity of modes of endoderm specification within ecdysozoans, a single population of endodermal cells specified at the vegetal pole of the embryo is likely the ancestral condition in the Ecdysozoa - as is likely observed in priapulids, and also in nematomorphs, most holoblastic cleaving arthropods, and out-group representatives of the Spiralia and Deuterostomia (Figure 6D,E). 


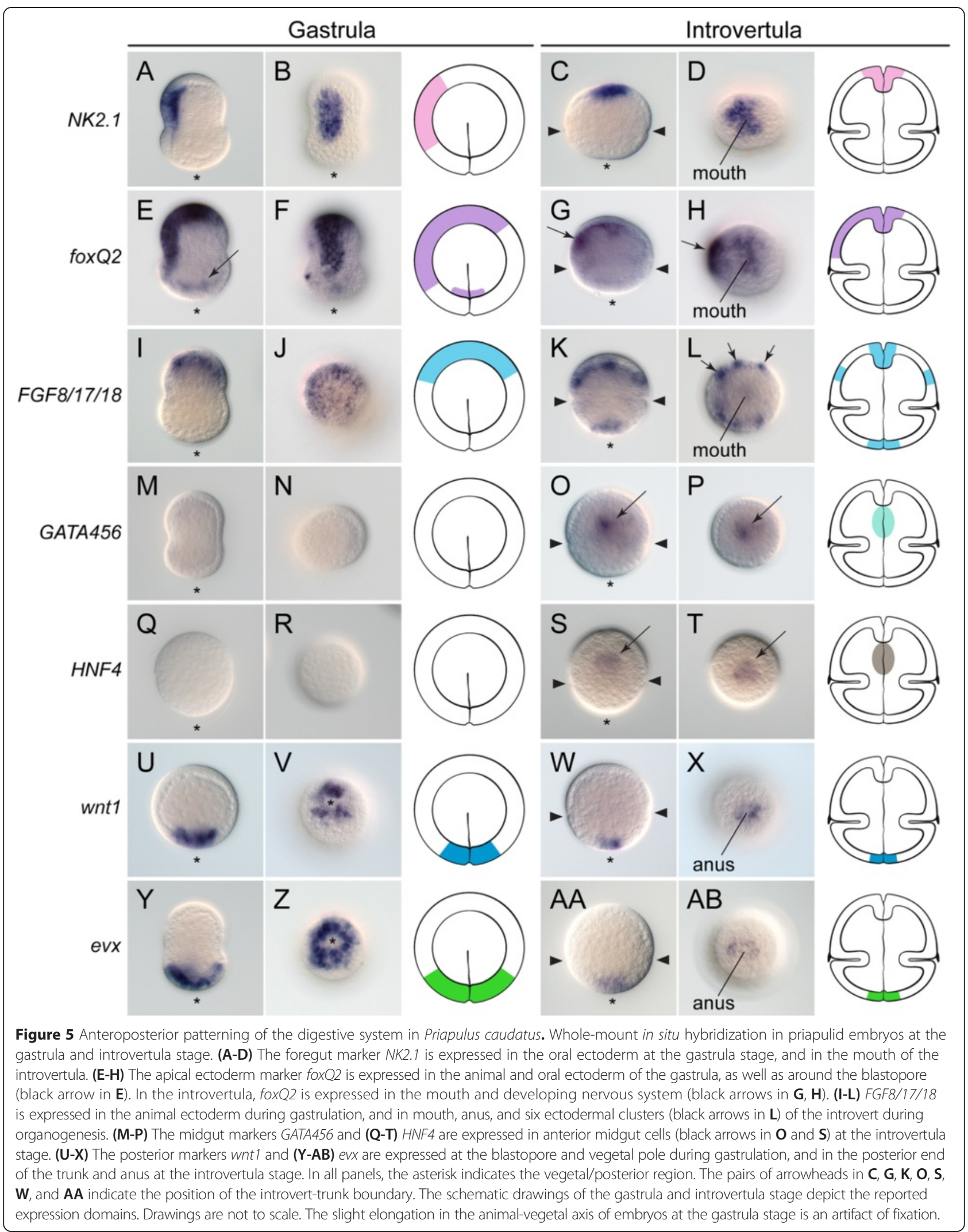




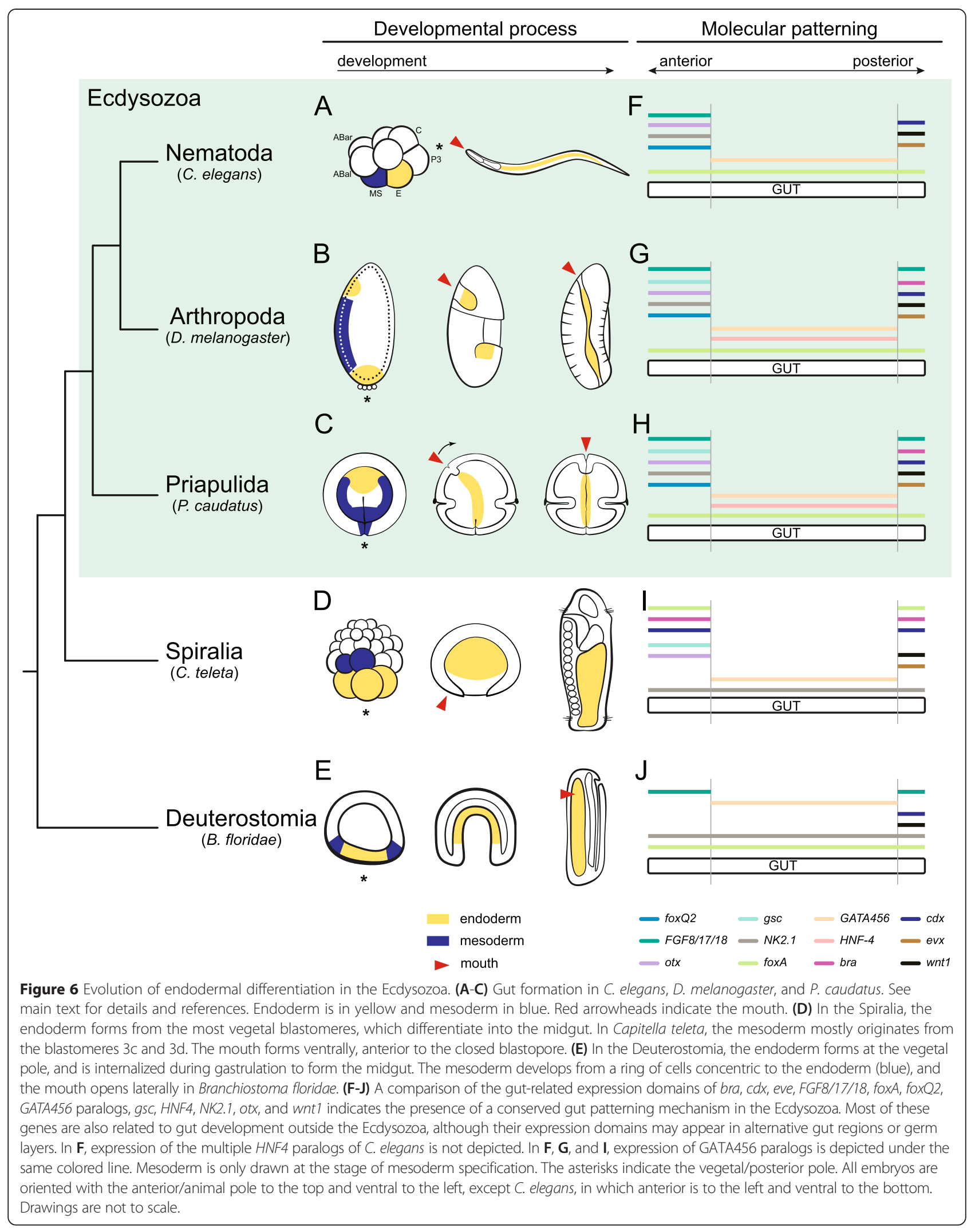


The organogenesis of a through gut from the primordial endodermal cells also varies among different ecdysozoan lineages. In C. elegans, the formation of the midgut occurs from a 16-cell primordium made of eight tiers of two cells each [18]. In this primordium, apical-basal cell polarization, lumen formation, and axial differentiation take place. The definitive midgut of the first larval stage strictly consists of 20 cells, and a similar olygocytose condition is observed in other members of the order Rhabditida and related taxa [54]. However, the majority of adult nematodes exhibit an intestine with hundreds or thousands of cells, which develops from a large midgut rudiment [54], and thus the situation observed in C. elegans is likely a derived condition. In most panarthropod embryos, the embryonic midgut is already made of multiple cells [10], as is also observed in D. melanogaster [25]. In P. caudatus embryos, the internal portion of the gut consists of 16 cells defining a tube and organized in three groups of four cells each and two posterior pairs of cells (Additional file 2: Video S1), a situation strikingly similar to the one described in C. elegans. However, successive rounds of molting seem to involve a general increase in the number of cells within the larval tissues and organs of $P$. caudatus (Figures 2 and 3), until reaching the polycytose situation of the intestine of adult priapulids. Notably, the priapulid hatching larva is non-feeding, as it lacks an oral and anal cuticular opening [39], and thus the olygocytose condition of the early post-embryonic intestine might be an adaptation to hatching with a yolk-rich immature gut. Taking everything into account, the development of a polycytose gut already during embryogenesis seems to be the ancestral condition in the Ecdysozoa.

\section{Mesoderm in $P$. caudatus and its relationship to endoderm development}

The endoderm often develops in close association with the mesoderm - the internal germ layer that generates the musculature, blood system, excretory organs, and skeleton - and thus the endoderm and mesoderm frequently influence each other's subsequent development $[4,5]$. In line with the variability in endoderm development observed in the Ecdysozoa, mesoderm segregation and differentiation also show great diversity [7,38]. In the nematode $C$. elegans, most larval mesoderm originates from the MS cell in the eight-cell stage embryo (Figure 6A), which is the sister cell of the endodermal E cell, both coming from the mother EMS cell in the fourcell stage embryo [21]. Ablation and cell culture studies have demonstrated that the $\mathrm{E}$ cell and its descendants have intrinsic properties to form polarized gut-like cells [18], and to pattern along the anteroposterior axis in a lineage-autonomous manner [72], although external factors and interactions with adjacent tissues, such as MS daughter cells [73] and the pharynx [74], are required for the proper definitive morphology of the digestive system. In early branching nematodes, there is no specification of the MS cell [53-55], and the formation of the embryonic midgut in relation to adjacent tissues has not been addressed. In the Nematomorpha, the exact origin of the mesoderm is not clear, although it appears as two lateral bands during gastrulation, surrounding the endoderm [58]. In the arthropod D. melanogaster, the mesoderm forms in the ventral region of the embryo, and is separated from the anterior and posterior midgut primordia by the foregut and hindgut ectoderm, respectively $[26,60]$ (Figure 6B). The ingression of the mesoderm creates a ventral furrow, and its differentiation into the visceral mesoderm is essential for the proper development of the midgut cells and the formation of a through gut [28]. This situation seems to be common to most winged insects [60] and some apterygote (wingless) insects [75]. In other yolk-rich panarthropod embryos, mesoderm development is more variable [10] and can occur from a small posteroventral area of the blastoderm (for example, onychophorans $[65,76]$ ), or from individual cells delaminating from the blastoderm (for example, in some myriapods [63]). By contrast, in those marine crustaceans with holoblastic cleavage and hollow blastulae, the mesoderm originates from a small subset of vegetal blastomeres internalized with the endoderm during gastrulation, usually in the form of two lateral bands $[10,69]$. Finally, in the tardigrade $T$. stephaniae, the mesoderm originates from a variable number of blastomeres that internalize and proliferate as two bands along the left and right sides of the embryo, giving rise to the somites [71].

The expression of the mesodermal gene twi in P. caudatus at the gastrula stage (Figure 3) indicates that mesoderm originates from the most vegetal/posterior endomesodermal cells of the gastrula, and extends anteriorly as two lateral rows. According to a previous study [35], these two lateral mesodermal rows form through active proliferation, rather than by continuous ingression of cells through the blastopore. No visceral musculature is formed during embryonic development (Figures 2 and 3), although the presence of visceral mesodermal precursors within the population of foxApositive gut cells remains a possibility. The visceral musculature thus probably appears in subsequent larval stages, given that this tissue is present in adult priapulids. However, the internal portion of the gut develops in close contact with the forming body wall musculature, and thus reciprocal interactions between endoderm and mesoderm cannot be completely excluded. Considering the different mechanisms observed in ecdysozoans, the ancestral mode of mesoderm formation is likely by the specification and internalization of mesodermal precursors along with the endodermal cells at the vegetal pole, 
and the formation of two lateral mesodermal bands through active proliferation that enclose the developing endoderm. Further functional investigations in P. caudatus and other ecdysozoan groups will be required to understand if the similarities in the interactions between the mesoderm and the endoderm observed in D. melanogaster and vertebrate embryos represent cases of convergence, or instead reflect ancestral developmental mechanisms.

\section{The question about the position of the mouth in the evolution of the Ecdysozoa}

Together with the midgut, the other two main regions of the digestive system in most bilaterian animals are the mouth (foregut) and the anus (hindgut). In the Ecdysozoa, the anus is of ectodermal origin, and forms at the posterior end, as in most other bilaterian groups, often ventrally and in relation to the site of gastrulation $[34,77,78]$. Differently from most other bilaterian animals, the mouth in adults of many ecdysozoan lineages is located at the most anterior tip of the body (terminal mouth), as observed in priapulids, kinorhynchs, loriciferans, nematodes, nematomorphs, tardigrades, and some arthropods (pycnogonids) (Figure 7A). Even stem group arthropods, such as fossil Cambrian lobopodians, exhibit an anterior terminal mouth [42]. This broad distribution has led to the current interpretation that the terminal mouth is an ancestral ecdysozoan character $[29,42]$ that has been secondarily located to a ventral position in extant adult onychophorans and arthropods [79]. A convergent ventralization of the mouth opening is observed in strongylid nematodes that derive from an ancestor that possessed a terminal mouth [80]. Despite this seemingly uniform adult position, the ontogeny of the mouth varies among ecdysozoan lineages (Figure 7A). In C. elegans the mouth opens in a terminal anterior position ([19] and Figure 6A), independently from the site of invagination of the E-cell descendants. While this seems to be true for most other related nematodes, the mouth seems to form from a ventral blastopore in the marine Enoplea [53,54]. In nematomorphs and tardigrades [58,71], the mouth forms at the anterior pole. In the insect D. melanogaster (Figure 6B), as in most other panarthropod embryos, the mouth forms ventrally and remains there $[10,26]$. Quite unusually, in many pycnogonids, the only arthropod group with an anterior terminal mouth in the adult, the oral opening forms anterodorsally with respect to the chelifores (buccal appendages), and then moves ventrally to an anterior terminal position $[36,81]$. This dorsoventral movement relative to the first appendage pair also occurs in euchelicerates, although in this case the mouth ends up ventrally [10]. Our study shows that the mouth emerges ventrally in the priapulid P. caudatus ([34] and Figures 2, 3, 4, 5, 6C, and 7A), and then shifts anterodorsally towards its definitive anterior terminal position. Our time-course analysis of cell proliferation suggests that differential proliferation in the ventral ectoderm of the introvert might support this morphogenetic movement, although further studies will be required to test how alternative mechanisms, such as convergent-extension and cell intercalation [82-84], contribute to this process. Priapulid development thus delivers a clear example for how a strictly terminal mouth in the adult can originate from the ventral side of the embryo. Given that in other bilaterian lineages the adult mouth and its embryonic anlage is most often ventral (Figures 6D,F and 7A), the most parsimonious conclusion is that the ventral opening of the mouth observed in the embryos of the Priapulida, Onychophora, and most lineages of the Arthropoda is likely the ancestral developmental condition for the Ecdysozoa (Figure 7B,C). More derived nematodes, nematomorphs, and tardigrades, which open the mouth at the anterior terminal pole, would have thus lost the original ventral formation of the mouth, probably related to its relatively late opening in development $[19,58,71]$. In addition, onychophorans and most arthropods, which do open the mouth ventrally during embryogenesis, might have lost its subsequent shift to a terminal position and thus retained the ventral location in the adult. This modification could have been associated with the evolution of more elaborate head appendages and complex dorsal brains in the arthropod lineage, and thus our data can also contribute to explaining the long-standing problem of the evolutionary and ontogenetic origins of head structures in arthropods [85].

\section{Conserved molecular patterning of the $P$. caudatus gut}

As discussed above, the ontogeny and adult architecture of the digestive system is highly variable between ecdysozoan lineages. This observation raises questions regarding the extent of differences in the molecular mechanisms underpinning gut development, and how these changes account for the manifest diversity of gut architectures. In the nematode C. elegans, endoderm specification is triggered by the maternally supplied $\mathrm{bZIP} /$ homeodomain gene $s k n-1$ (related to the $n r f 2$ gene of vertebrates, and the cap'n'collar gene of D. melanogaster), which is required for proper specification of the ventral EMS cell [86]. After the division of this cell, $s k n$ 1 activates a cascade of redundant pairs of GATA factors (med-1, med-2, end-1, end-3, elt-2, elt-4, and elt-7) that will lead to the establishment of endodermal fate in the E cell [87], but not in the MS cell [88]. The Wnt pathway is also involved in this process [89], although this seems to be related to its general role in segregating cell fates along the anteroposterior axis [90]. Additionally, the transcription factor pha-4, an ortholog of the 


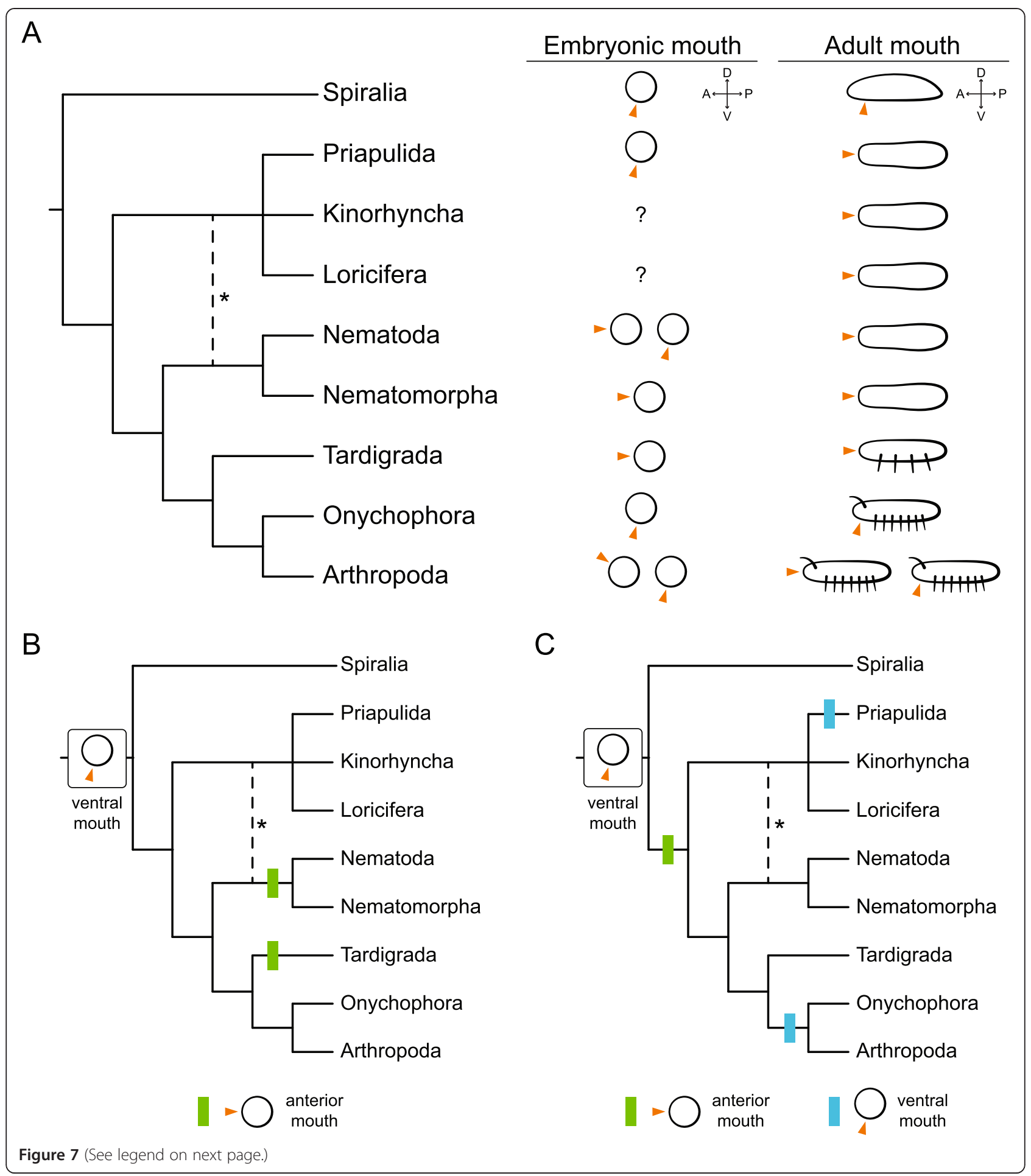


(See figure on previous page.)

Figure 7 The evolution of the position of the mouth in the Ecdysozoa. (A) Diversity of mouth position in embryos and adults of the different ecdysozoan lineages. While in the Spiralia the mouth forms ventrally, and stays ventral in the adult, this situation is more variable in the Ecdysozoa. The mouth can form ventrally (priapulids, some nematodes, onychophorans, and most arthropods), at an anterior terminal position (most nematodes, nematomorphs, and tardigrades), or even on the dorsal site (in the pycnogonid arthropods). However, in the adults the mouth occupies an anterior terminal position, except in extant onychophorans and most arthropods (pycnogonids have a terminal mouth). While an anterior terminal mouth in the adult seems to be ancestral for the Ecdysozoa, the original embryonic position has been debated. (B) Evolutionary scenario of an ancestral ventral embryonic mouth. In this situation, independent modifications occurred in the Nematoida and Tardigrada that led to the late formation of the mouth at a terminal position. (C) Evolutionary scenario of an ancestral anterior embryonic mouth. In this situation, the embryonic mouth shifted to an anterior position at the base of the Ecdysozoa, and was secondarily reverted to a ventral site in priapulids and pan-arthropods, which is less parsimonious than assuming an ancestral ventral embryonic mouth (see B). For the sake of clarity, the ventral mouth of certain nematodes and the dorsal mouth of pycnogonids have not been considered in B or $\mathbf{C}$. In A-C, the asterisk indicates the alternative branching of the Scalidophora (Priapulida, Kinorhyncha, Loricifera) together with the Nematoida to form what has been proposed as the Cycloneuralia clade. See main text for references. Drawings are not to scale.

endodermal marker fox $A$, is expressed throughout the pharynx and midgut [91-93], and orthologs of NK2.1, otx, FGF8/17/18, and foxQ2 (C25A1.2) are expressed and/or involved in pharynx development [19,46,94-96]. In nematodes, the nuclear hormone receptor family, and in particular the endodermal-related HNF4, has undergone extreme duplication [97], and many of the paralogs are expressed in different regions of the digestive system [98]. The posterior region and the hindgut, which consists of eight cells derived from the ABp blastomere [21], also show expression of wnt1, evx, T-box genes (not bra, which seems to be absent in C. elegans), $c d x$, and pha-4 (foxA), among others [93,99-101] (see Figure 6F for a summary of expression data). In D. melanogaster, the specification of the midgut primordia is controlled by the terminal gap-gene huckebein $(h k b)$, which controls endoderm specification at the amnioproctodeal invagination (posterior midgut), invagination of the anterior midgut, and specification of mesodermal precursors at the ventral furrow [102]. In D. melanogaster, $h k b$ is a core component of the terminal patterning system, a development pathway involved in setting up the anterior and posterior ends of the embryo in hexapod arthropods $[103,104]$. However, its enrolment in this developmental pathway seems to be an evolutionary novelty, probably unique to D. melanogaster and closely related species, and its ancestral function was likely related to the nervous system [103]. The transcription factor forkhead (foxA); the GATA genes serpent, grain, and dGATAe (orthologs of the GATA456 subfamily); and the nuclear hormone receptor HNF4 are subsequently required for proper midgut development in D. melanogaster [105-107]. Additionally, other genes such as NK2.1, gsc, otx, foxQ2, and $F G F 8 / 17 / 18$ are involved in the patterning of the head and foregut $[47,49,108-110]$, and the genes bra, $c d x, w n t 1$, $e v x, F G F 8 / 17 / 18$, and also fox $A$ are required for the proper formation and patterning of the posterior region of the embryo [106,111-114] (Figure 6G). In the priapulid $P$. caudatus, the expression patterns of most of these genes exhibit significant similarities to the expression domains reported for $C$. elegans and D. melanogaster (Figure $6 \mathrm{H}$ ). The F-box containing protein fox $A$ is expressed in the foregut and inner gut [34], while a single GATA456 gene and the HNF4 ortholog are expressed in the anterior region of the internal alimentary canal. Together with gsc and otx [34], NK2.1, foxQ2, and FGF8/17/ 18 are expressed in the foregut, while $w n t 1, e v x$, and also FGF8/17/18 are detected in the ectodermal anus, as well as bra and $c d x$ [34]. The expression of the endodermal midgut markers GATA456 and HNF4 is likely limited to the three most anterior tetrads of the internal gut, and the observation of the hindgut genes foxA, bra, and $c d x$ [34] in the region corresponding to the two most posterior duplets could indicate that these regions correspond to the endodermal midgut and internal ectodermal hindgut of the priapulid embryo, respectively. More detailed cell lineage analyses will be required to confirm this hypothesis. Although functional data are still lacking in P. caudatus, the comparison of expression data with that of the nematode C. elegans and the insect D. melanogaster reveals important similarities between these lineages of ecdysozoans (Figure 6F-H), mostly during the stages in which the gut is patterned into the three main regions. Notably, the overall patterning of the digestive system appears to be more conserved between $P$. caudatus and D. melanogaster, although $P$. caudatus and C. elegans would be considered morphologically more similar $[115,116]$. C. elegans differs mostly by the absence (for example, gsc and bra) or expansion (GATA456, HNF4) of some of the studied genes, which might be related to its high rate of genome evolution [117]. Similarly, the differences in the earliest steps of endoderm development between $C$. elegans and D. melanogaster are probably due to their idiosyncratic early embryogenesis, as has also been shown in other bilaterian animals [6], and thus further work is needed to address the ancestral mechanism of endoderm specification for the Ecdysozoa. Nevertheless, our data on P. caudatus support the existence of a conserved molecular patterning program for the digestive system in the Ecdysozoa, despite the great differences in developmental modes and gut architectures. 
The expression patterns of the above investigated genes in representative members of the ecdysozoan out-groups Spiralia (for example, the annelid Capitella teleta; Figure 6I) and Deuterostomia (for example, Branchiostoma floridae; Figure 6J) demonstrate that a similar system is also involved in gut regionalization outside the Ecdysozoa [48,51,52,118-128], although, in these organisms, the expression domains of particular genes often occur in, and extend to, different regions and germ layers. This observation, together with the similarities observed between $P$. caudatus, C. elegans, and D. melanogaster, strengthens the hypothesis of an ancestral molecular gut patterning system that is shared to a great extent between all the Ecdysozoa, despite morphological and developmental deviations being present in particular groups. Importantly, the molecular machinery that underlies early gut development in animals is much more similar than the developmental modes they undertake and the adult gut architectures they display (Figure 6). Therefore, the study of this common developmental toolkit alone cannot explain the vast morphological diversity of digestive tracts in animals. Differences in expression domains indicate that gene interactions and regulatory networks are probably variable, influenced by distinct developmental modes, early molecular/maternal inputs, and, most importantly, downstream effectors. Ultimately, the diversity of gut architectures also relies on molecular differences at more advanced stages of development. For instance, GATA factors activate effector genes required for intestinal cell differentiation in C. elegans $[88,129,130]$, while triggering the epithelial-to-mesenchymal transition of the midgut primordia in the fly [107]. In a more general context, our study shows that the investigation of general patterning mechanisms between animals cannot lead to the prediction of a morphological outcome. A deeper understanding of the vast morphological diversity of animal forms can thus only be gained by broader taxon sampling and the consideration in developmental studies of the more terminal ontogenetic events that are ultimately responsible for the final morphological outcomes.

\section{Conclusion}

Our comparative study of the development of $P$. caudatus, a representative of the sister group to all remaining ecdysozoans, shows that there are some primary features in the development of the digestive system that are likely to be ancestral for the Ecdysozoa, namely the formation of the endodermal midgut region from a single population of vegetal cells internalized during gastrulation, the ventral opening of the mouth and its subsequent shift to an anterior terminal position, and the development of the anus from the blastopore. Over evolutionary time, these characters have undergone great diversification and adaptation, as exemplified by the modes of gut development present in the two textbook invertebrate models, the nematode $C$. elegans and the fruit fly $D$. melanogaster. However, these extreme developmental divergences do not seem to be associated with a similar extent of molecular innovation in upstream patterning systems, as common transcriptional expression profiles are observed during the early stages of gut assembly among different ecdysozoan lineages. Our data not only shed light on the unexplored embryogenesis of the Priapulida and the evolution of the Ecdysozoa, but, importantly, also improve our understanding of the evolutionary changes that occurred in the lineages leading to C. elegans and D. melanogaster.

\section{Methods}

\section{Animal collection, fertilization, and embryo fixation}

Adult gravid specimens of $P$. caudatus were collected from Gullmarsfjorden (Fiskebäckskil, Sweden) in November in 2011, 2012 and 2013. Ovaries and testes were dissected, and kept in filtered deep seawater (FDSW). Oocytes were released by shaking the ovaries, and were fertilized with active diluted sperm from several males. Fertilized eggs were kept in petri dishes with FDSW at a constant temperature of $9^{\circ} \mathrm{C}$, and washed daily with fresh FDSW to avoid bacterial and protozoan contamination. Embryos hatched 9 days after fertilization, and hatching larvae molted to the first lorica larvae 1 week thereafter, without any added food source. Before fixation, embryos were permeabilized with $0.05 \%$ thioglycolate, $0.01 \%$ pronase in FDSW for $45 \mathrm{~min}$ at $9^{\circ} \mathrm{C}$. After three washes in FDSW, embryos were fixed in $4 \%$ paraformaldehyde in FDSW for $1 \mathrm{~h}$ at room temperature, followed by three washes in phosphate-buffered saline (PBS) with $0.1 \%$ Tween-20 (PTw). Hatching larvae and first lorica larvae were relaxed in $0.1 \%$ tricaine in FDSW for $30 \mathrm{~s}$ and fixed immediately in $4 \%$ paraformaldehyde in FDSW for $1 \mathrm{~h}$ at room temperature. Embryos and larvae fixed for immunohistochemical studies were stored in $0.1 \%$ sodium azide in PTw at $4^{\circ} \mathrm{C}$. Samples fixed for gene expression studies were dehydrated in 50\% methanol in PTw, washed once in $100 \%$ methanol, and stored in methanol at $-20^{\circ} \mathrm{C}$.

\section{Proliferation studies}

Cell proliferation was observed by the incorporation of the thymidine analog EdU during DNA replication. Batches of embryos at days $3.5(n=18), 4.5(n=16)$, and $5.5(n=19)$ of development were incubated for $3 \mathrm{~h}$ in FDSW supplemented with $10 \mu \mathrm{M}$ EdU. After this pulse, the medium was changed several times to remove any traces of EdU. Treated embryos were permeabilized and fixed as described above, $6 \mathrm{~h}, 12 \mathrm{~h}$, and $24 \mathrm{~h}$ after the start of the EdU pulse, and stored in $0.1 \%$ sodium azide in $\mathrm{PTw}$ at $4^{\circ} \mathrm{C}$. Fluorescent labeling of the incorporated 
EdU was performed as recommended by the Click-it EdU Alexa Fluor 488 imaging kit (Life Technologies, NY, USA), and nuclei were counterstained with $0.01 \mathrm{mg} / \mathrm{mL}$ propidium iodide.

\section{Phallacidin labeling}

Embryos fixed and stored for immunohistochemical studies were washed several times in PBS before staining. Actin filaments and nuclei were labeled with $5 \mathrm{U} / \mathrm{mL}$ of Bodipy-FL phallacidin (Life Technologies, NY, USA) and $0.01 \mathrm{mg} / \mathrm{mL}$ propidium iodide (Sigma-Aldrich Chemie Gmbh Munich, Germany) in PBT (PBS, 0.2\% TritonX-100, 0.1\% bovine serum albumin) for $1 \mathrm{~h}$ at room temperature. Thereafter, embryos were washed in PBS for $1 \mathrm{~h}$, dehydrated in a graded isopropanol series $(70 \%, 85 \%, 95 \%$ in PBS, and twice in $100 \%$ for 30 to $60 \mathrm{~s}$ each) and cleared in Murray's reagent (benzyl benzoate to benzyl alcohol, 2:1, v:v).

\section{Gene expression studies}

A fragment of $N K 2.1$, and the full-length sequences of foxQ2, FGF8/17/18, GATA456, HNF4, wnt1, evx, and twi [GenBank: KP013750-KP013757] were identified from RNAseq data. Protein alignments were constructed with MAFFT [131], and poorly aligned regions were removed with Gblocks [132]. RAxML [133] was used to infer gene orthologies (Additional file 5: Figure S4). Resulting trees were formatted with FigTree. Single colorimetric in situ hybridization was performed as described in [34]. Fluorescent in situ hybridization of foxA in EdU-treated embryos was performed following the regular colorimetric protocol up to antibody incubation, when samples were incubated overnight with an anti-DIG POD-conjugated antibody (Roche, Indianapolis, IN, USA) diluted 1:250 in blocking solution. After extensive washes, the signal was developed with a TSA-Cy3 kit (Perkin-Elmer, Waltham, MA, USA) following manufacturer's recommendations. The TSA reaction was stopped in detergent solution $(1 \%$ Triton X-100, 1\% SDS, $0.5 \%$ sodium deoxycholate, $50 \mathrm{mM}$ Tris $\mathrm{pH} 8,150 \mathrm{mM} \mathrm{NaCl}$ ) at $60^{\circ} \mathrm{C}$, and embryos washed several times in PTw afterwards. Subsequent fluorescent labeling of the EdU incorporation in these embryos was performed as suggested by the EdU kit manufacturer (Life Technologies).

\section{Imaging}

Fluorescence-stained embryos and larvae cleared in Murray's reagent were scanned with a Leica SP5 confocal laser scanning microscope (Leica, Wetzlar, Germany). Embryos exhibiting representative expression patterns of the analyzed genes were cleared in 70\% glycerol in PTw, and imaged with a Zeiss Axiocam HRc connected to a Zeiss Axioscope Ax10 using bright field Nomarski optics (Zeiss, Oberkochen, Germany). Images were analyzed in Fiji and Photoshop CS6 (Adobe), and figure plates made with Illustrator CS6 (Adobe).

\section{Additional files}

Additional file 1: Figure S1. Cellular organization of the digestive system of Priapulus caudatus. z projections of confocal stacks of an embryo at day 6 of development stained with phallacidin (green) and propidium iodide (magenta). (A) Lateral view, with the digestive system fully developed: the mouth occupies an anterior terminal position, the midgut runs all along the embryo, and the anus opens posteriorly. The introvert-trunk boundary is well formed, and the scalids are visible. (B) Section of the introvert at the level of the mouth. Ectodermal cells of the mouth form a monostratified epithelium, with the apical side of the cells constricted and delimiting the lumen. Notice the connection of the mouth with the introvert ectoderm (white arrow), which corresponds to the neuroectoderm. (C, D) Sections through the midgut at the level of the introvert and trunk, respectively. Tiers of four cells delimit the central gut lumen. (E) Section of the trunk at the level of the ectodermal hindgut. In A, anterior to the top. The pair of arrowheads in A indicate the position of the introvert-trunk boundary, and the dashed lines the position of the transverse sections displayed on B-E). an, anus; dg, digestive system; lu, lumen; mc, muscles; mo, mouth; sc, scalids. Scale bars, $50 \mu \mathrm{m}$.

Additional file 2: Video S1. Structure of the embryonic digestive system. Video of a confocal stack of a 6-day-old embryo imaged along the anteroposterior axis. The morphology of the internal alimentary canal can be observed, as well as the morphology and distribution of ectodermal introvert cells.

Additional file 3: Figure S2. Model for the retraction of the introvert. (A) The introvert-trunk boundary corresponds to the external introvert epidermis, neck, and part of the trunk epidermis, while the animal hemisphere ectoderm corresponds to the mouth and the oral cavity. (B) Before introvert retraction, the mouth moves to an anterior terminal position. (C) The retraction of the introvert starts when the introvert-trunk boundary unfolds, which pushes inwards the mouth and the oral cavity. This process is likely controlled by muscle contraction. (D) At the end of development, the introvert is retracted, the trunk completely covers the embryo, and the neck region lies at the top of the embryo. (E) When the hatching larva protrudes the introvert, the buccal cavity with the scalids and the mouth are projected anteriorly. The pairs of black arrowheads indicate the introvert-trunk boundary. All embryonic stages and the hatching larva are oriented with the anterior to the top. Drawings are not to scale. an, anus; dg, digestive system; mo, mouth; sc, scalids.

Additional file 4: Figure S3. Position of EdU-positive cells during mouth development. ( $\left.\mathbf{A}^{\prime}-\mathbf{A}^{\prime \prime \prime}\right)$ z projections of confocal stacks of an embryo after 4.5 days of development labeled for EdU-positive cells (green) and foxApositive expressing cells (magenta). The mouth marker foxA is expressed ventrally at the mouth ectoderm [34], and co-localizes with the EdU proliferative cells, which are thus present around the mouth region (mo) and ventral side of the introvert. (B) z projections of a confocal stacks of an embryo at a similar developmental time point, showing that nuclei distribute more or less uniformly throughout the introvert ectoderm, but slightly more densely packed in the ventral midline and mouth area (delimited by the dotted line), which corresponds to the EdU-positive region in $A$. $A^{\prime}-B$, anterior views. Scale bars, $25 \mu \mathrm{m}$.

Additional file 5: Figure S4. Analyses of gene orthology. (A-H) Maximum likelihood phylogenetic trees of twi, NK2.1, foxQ2, FGF8/17/18, GATA456, HNF4, wnt1, and evx. Replicate bootstrap values were calculated with the autoMRE option in RAxML. P. caudatus sequences are highlighted in red. Models of protein evolution used for each tree: twi, JTT; NK2.1, RtREV; foxQ2, WAG; FGF8/17/18, WAG + F; GATA456, JTT; HNF4, LG; wnt1, WAG; and evx, LG.

\section{Competing interests}

The authors declare that they have no competing interests.

\section{Authors' contributions}

JMMD and AH designed the study. JMMD performed the experiments. JMMD and AH analyzed the data and wrote the manuscript. Both authors read and approved the final manuscript. 


\section{Acknowledgements}

We thank the members of the Hejnol laboratory for support and discussions, Gemma S. Richards for a critical read of the manuscript, the staff at the Sven Lovén Centre for Marine Sciences for helping with the collections, and the two anonymous reviewers for their helpful comments. The study was funded by the core budget of the Sars Centre, and the collection trips were funded by the European Union Infrastructures Program (ASSEMBLE grant agreement no. 227799). JMMD is supported by Marie Curie IEF 329024 fellowship.

\section{Received: 26 November 2014 Accepted: 13 April 2015}

\section{Published online: 21 April 2015}

\section{References}

1. Schmidt-Rhaesa A. The evolution of organ systems. Oxford: Oxford University Press; 2007.

2. Nielsen C. Animal evolution. Oxford: Oxford University Press; 2012.

3. Clements $D, \operatorname{Rex} M$, Woodland HR. Initiation and early patterning of the endoderm. Int Rev Cytol. 2001;203:383-446.

4. Stainier DY. No organ left behind: tales of gut development and evolution. Science. 2005:307:1902-4

5. Stainier DY. A glimpse into the molecular entrails of endoderm formation. Genes Dev. 2002;16:893-907.

6. Grapin-Botton A, Constam D. Evolution of the mechanisms and molecular control of endoderm formation. Mech Dev. 2007;124:253-78.

7. Gilbert SF. Developmental biology. Sunderland, MA: Sinauer Associates; 2013.

8. Arendt D, Nübler-Jung K. Rearranging gastrulation in the name of yolk: evolution of gastrulation in yolk-rich amniote eggs. Mech Dev. 1999:81:3-22.

9. Martín-Durán JM, Egger B. Developmental diversity in free-living flatworms. EvoDevo. 2012:3:7.

10. Anderson DT. Embryology and phylogeny in annelids and arthropods. Oxford: Pergamon Press; 1973.

11. Aboobaker AA, Blaxter ML. Medical significance of Caenorhabditis elegans. Ann Med. 2000;32:23-30.

12. Bernards A, Hariharan IK. Of flies and men - studying human disease in Drosophila. Curr Opin Genet Dev. 2001;11:274-8.

13. O'Kane CJ. Modelling human diseases in Drosophila and Caenorhabditis. Semin Cell Dev Biol. 2003;14:3-10.

14. Aguinaldo AM, Turbeville JM, Linford LS, Rivera MC, Garey JR, Raff RA, et al. Evidence for a clade of nematodes, arthropods and other moulting animals. Nature. 1997;387:489-93

15. Dunn CW, Hejnol A, Matus DQ, Pang K, Browne WE, Smith SA, et al. Broad phylogenomic sampling improves resolution of the animal tree of life. Nature. 2008:452:745-9.

16. Dunn CW, Giribet G, Edgecombe GD, Hejnol A. Animal phylogeny and its evolutionary implications. Annu Rev Ecol Evol Syst. 2014;45:371-95.

17. Hejnol A, Obst M, Stamatakis A, Ott M, Rouse GW, Edgecombe GD, et al. Assessing the root of bilaterian animals with scalable phylogenomic methods. Proc Biol Sci. 2009;276:4261-70.

18. Leung B, Hermann GJ, Priess JR. Organogenesis of the Caenorhabditis elegans intestine. Dev Biol. 1999;216:114-34.

19. Portereiko MF, Mango SE. Early morphogenesis of the Caenorhabditis elegans pharynx. Dev Biol. 2001;233:482-94.

20. Chamberlin HM, Brown KB, Sternberg PW, Thomas JH. Characterization of seven genes affecting Caenorhabditis elegans hindgut development. Genetics. 1999;153:731-42.

21. Sulston JE, Schierenberg E, White JG, Thomson JN. The embryonic cell lineage of the nematode Caenorhabditis elegans. Dev Biol. 1983;100:64-119.

22. Goldstein B. Induction of gut in Caenorhabditis elegans embryos. Nature. 1992;357:255-7

23. Goldstein B. Establishment of gut fate in the $E$ lineage of $C$. elegans: the roles of lineage-dependent mechanisms and cell interactions. Development. 1993;118:1267-77.

24. Goldstein B. An analysis of the response to gut induction in the C. elegans embryo. Development. 1995;121:1227-36.

25. Lemaitre B, Miguel-Aliaga I. The digestive tract of Drosophila melanogaster. Annu Rev Genet. 2013;47:377-404.

26. Hartenstein V, Technau GM, Campos-Ortega JA. Fate-mapping in wild-type Drosophila melanogaster. Roux Arch Dev Biol. 1985;194:213-6.

27. Hartenstein V. Atlas of Drosophila development. Cold Spring Harbor, NY: CSHL Press; 1993.
28. Tepass $U$, Hartenstein V. Epithelium formation in the Drosophila midgut depends on the interaction of endoderm and mesoderm. Development. 1994;120:579-90.

29. Borner J, Rehm P, Schill RO, Ebersberger I, Burmester T. A transcriptome approach to ecdysozoan phylogeny. Mol Phylogenet Evol. 2014;80:79-87.

30. Schmidt-Rhaesa A. Priapulida. In: Schmidt-Rhaesa A, editor. Handbook of zoology - Nematomorpha, Priapulida, Kinorhyncha, Loricifera, vol. 1. Berlin: Walter e Gruyter GmbH; 2013. p. 147-80.

31. Huang DY, Vannier J, Chen JY. Recent Priapulidae and their Early Cambrian ancestors: comparisons and evolutionary significance. Geobios. 2004;37:217-28.

32. Vannier J, Calandra I, Gaillard C, Żylińska A. Priapulid worms: pioneer horizontal burrowers at the Precambrian-Cambrian boundary. Geology. 2010;38:711-4

33. Storch V. Priapulida. In: Harrison FW, Ruppert EE, editors. Microscopic anatomy of invertebrates, vol. 4: Aschelminthes. New York, NY: Wiley-Liss; 1991. p. 333-50.

34. Martín-Durán JM, Janssen R, Wennberg S, Budd GE, Hejnol A. Deuterostomic development in the protostome Priapulus caudatus. Curr Biol. 2012;22:2161-6.

35. Wennberg SA, Janssen R, Budd GE. Early embryonic development of the priapulid worm Priapulus caudatus. Evol Dev. 2008:10:326-38.

36. Ungerer $P$, Scholtz $G$. Cleavage and gastrulation in Pycnogonum litorale (Arthropoda, Pycnogonida): morphological support for the Ecdysozoa? Zoomorphology. 2009;128:263-74.

37. Webster BL, Copley RR, Jenner RA, Mackenzie-Dodds JA, Bourlat SJ, Rota-Stabelli $\mathrm{O}$, et al. Mitogenomics and phylogenomics reveal priapulid worms as extant models of the ancestral Ecdysozoan. Evol Dev. 2006;8:502-10.

38. Stern CD. Gastrulation: from cells to embryo. Cold Spring Harbor, NY: CHSL Press; 2004.

39. Wennberg S, Janssen R, Budd GE. Hatching and earliest larval stages of the priapulid worm Priapulus caudatus. Inv Biol. 2009;128:157-71.

40. Price $\mathrm{AL}$, Patel $\mathrm{NH}$. Investigating divergent mechanisms of mesoderm development in arthropods: the expression of Ph-twist and Ph-mef2 in Parhyale hawaiensis. J Exp Zool B Mol Dev Evol. 2008;310:24-40.

41. Technau U, Scholz CB. Origin and evolution of endoderm and mesoderm. Int J Dev Biol. 2003:47:531-9.

42. Budd GE. Tardigrades as 'stem-group arthropods': the evidence from the Cambrian fauna. Zool Anz. 2001;240:265-79.

43. Takacs CM, Moy VN, Peterson KJ. Testing putative hemichordate homologues of the chordate dorsal nervous system and endostyle: expression of NK2.1 (TTF-1) in the acorn worm Ptychodera flava (Hemichordata, Ptychoderidae). Evol Dev. 2002;4:405-17.

44. Santagata S, Resh C, Hejnol A, Martindale MQ, Passamaneck YJ. Development of the larval anterior neurogenic domains of Terebratalia transversa (Brachiopoda) provides insights into the diversification of larval apical organs and the spiralian nervous system. EvoDevo. 2012;3:3.

45. Fritzenwanker JH, Gerhart J, Freeman Jr RM, Lowe CJ. The Fox/Forkhead transcription factor family of the hemichordate Saccoglossus kowalevskii. EvoDevo. 2014;5:17.

46. Hope IA, Mounsey A, Bauer P, Aslam S. The forkhead gene family of Caenorhabditis elegans. Gene. 2003:304:43-55.

47. Lee HH, Frasch M. Survey of forkhead domain encoding genes in the Drosophila genome: classification and embryonic expression patterns. Dev Dyn. 2004;229:357-66.

48. Bertrand S, Camasses A, Somorjai I, Belgacem MR, Chabrol O, Escande ML, et al. Amphioxus FGF signaling predicts the acquisition of vertebrate morphological traits. Proc Natl Acad Sci U S A. 2011;108:9160-5.

49. Stathopoulos A, Tam B, Ronshaugen M, Frasch M, Levine M. Pyramus and thisbe: FGF genes that pattern the mesoderm of Drosophila embryos. Genes Dev. 2004;18:687-99.

50. Petersen CP, Reddien PW. Wnt signaling and the polarity of the primary body axis. Cell. 2009;139:1056-68.

51. Ferrier DE, Minguillon C, Cebrian C, Garcia-Fernandez J. Amphioxus Evx genes: implications for the evolution of the Midbrain-Hindbrain Boundary and the chordate tailbud. Dev Biol. 2001;237:270-81.

52. Seaver EC, Yamaguchi E, Richards GS, Meyer NP. Expression of the pair-rule gene homologs runt, Pax3/7, even-skipped-1 and even-skipped-2 during larval and juvenile development of the polychaete annelid Capitella teleta does not support a role in segmentation. EvoDevo. 2012;3:8.

53. Schulze J, Schierenberg E. Evolution of embryonic development in nematodes. EvoDevo. 2011;2:18. 
54. Malakhov AA. Nematodes. Structure, development, classification, and phylogeny. Washington, DC: Smithsonian Institution Press; 1994.

55. Voronov DA, Panchin Y. Cell lineage in marine nematode Enoplus brevis. Development. 1998;125:143-50.

56. Goldstein B. On the evolution of early development in the Nematoda. Philos Trans R Soc Lond B Biol Sci. 2001;356:1521-31.

57. Schierenberg E. Unusual cleavage and gastrulation in a freshwater nematode: developmental and phylogenetic implications. Dev Genes Evol. 2005;215:103-8.

58. Montgomery TH. The development and structure of the larva of Paragordius. Proc Natl Acad Sci Phila. 1904;56:738-55.

59. Inoue I. Studies on the life history of Chordodes japonensis, a species of Gordiacea. I. The development and structure of the larva. Jap J Zool. 1958;12:203-18.

60. Roth S. Gastrulation in other insects. In: Stern CD, editor. Gastrulation from cells to embryo. Cold Spring Harbor, NY: CSHL Press; 2004. p. 105-22.

61. Schröder R, Eckert C, Wolff C, Tautz D. Conserved and divergent aspects of terminal patterning in the beetle Tribolium castaneum. Proc Natl Acad Sci U S A. 2000;97:6591-6.

62. Dohle W. Die Embryonalentwicklung von Glomeris marginata (Villers) im Vergleich zur Entwicklung anderer Diplopoden. Zool Jb Anat Ont. 1964;81:241-310.

63. Tiegs OW. The embryology and affinities of the Symphyla, based on a study of Hanseniella agilis. Q J Microsc Sci. 1947;82:1-225.

64. Manton SM. Studies on the Onychophora VII: the early embryonic stages of Peripatopsis and some general considerations concerning the morphology and phylogeny of the Arthropoda. Philos Trans R Soc Lond B Biol Sci. 1949;233:483-580

65. Eriksson BJ, Tait NN. Early development in the velvet worm Euperipatoides kanangrensis Reid 1996 (Onychophora: Peripatopsidae). Arthropod Struct Dev. 2012:41:483-93.

66. Wolff $\mathrm{C}$, Hilbrant M. The embryonic development of the central American wandering spider Cupiennius salei. Front Zool. 2011:8:15.

67. Kimble M, Coursey Y, Ahmad N, Hinsch GW. Behavior of the yolk nuclei during embryogenesis, and development of the midgut diverticulum in the horseshoe crab Limulus polyphemus. Invert Biol. 2002;121:365-77.

68. Hertzler PL. Cleavage and gastrulation in the shrimp Penaeus (Litopenaeus) vannamei (Malacostraca, Decapoda, Dendrobranchiata). Arthropod Struct Dev. 2005:34:455-69.

69. Biffis C, Alwes F, Scholtz G. Cleavage and gastrulation of the dendrobranchiate shrimp Penaeus monodon (Crustacea, Malacostraca, Decapoda). Arthropod Struct Dev. 2009;38:527-40.

70. Gerberding M, Patel NH. Gastrulation in crustaceans: germ layers and cell lineages. In: Stern CD, editor. Gastrulation: from cells to embryo. Cold Spring Harbor, NY: CSHL Press; 2004

71. Hejnol A, Schnabel R. The eutardigrade Thulinia stephaniae has an indeterminate development and the potential to regulate early blastomere ablations. Development. 2005;132:1349-61.

72. Schroeder DF, McGhee JD. Anterior-posterior patterning within the Caenorhabditis elegans endoderm. Development. 1998;125:4877-87.

73. Hermann GJ, Leung B, Priess JR. Left-right asymmetry in C. elegans intestine organogenesis involves a LIN-12/Notch signaling pathway. Development. 2000;127:3429-40.

74. Rasmussen JP, Feldman JL, Reddy SS, Priess JR. Cell interactions and patterned intercalations shape and link epithelial tubes in C elegans. PLoS Genet. 2013;9:e1003772.

75. Woodland JT. A contribution to our knowledge of lepismatid development. J Morph. 1957:101:523-77.

76. Anderson DT. The comparative early embryology of the Oligochaeta, Hirudinea and Onychophora. Proc Linn Soc NSW. 1966;91:10-43.

77. Janssen $R$, Jörgensen M, Lagebro L, Budd GE. Fate and nature of the onychophoran mouth-anus furrow and its contribution to the blastopore. Proc R Soc B. 2015;282:20142628.

78. Hejnol A, Martín-Durán JM. Getting to the bottom of anal evolution. Zool Anz. 2015, in press. http://dx.doi.org/10.1016/j.jcz.2015.02.006.

79. Budd GE. A palaeontological solution to the arthropod head problem. Nature. 2002:417:271-5.

80. Fitch DH, Sudhaus W. One small step for worms, one giant leap for "Bauplan"? Evol Dev. 2002;4:243-6.

81. Machner J, Scholtz G. A scanning electron microscopy study of the embryonic development of Pycnogonum litorale (Arthropoda, Pycnogonida). J Morphol. 2010;271:1306-18.
82. Leptin M. Gastrulation movements: the logic and the nuts and bolts. Dev Cell. 2005:8:305-20.

83. Steinmetz PRH, Zelada-Gonzales F, Burgtorf C, Wittbrodt J, Arendt D. Polychaete trunk neuroectoderm converges and extends by mediolateral cell intercalation. Proc Natl Acad Sci U S A. 2007;104:2727-32.

84. Irvine KD, Wieschaus E. Cell intercalation during Drosophila germband extension and its regulation by pair-rule segmentation genes. Development. 1994;120:827-41.

85. Rempel JG. The evolution of the insect head: the endless dispute. Q Entomol. 1975;11:7-25.

86. Bowerman B, Eaton BA, Priess JR. skn-1, a maternally expressed gene required to specify the fate of ventral blastomeres in the early $C$. elegans embryo. Cell. 1992;68:1061-75.

87. Zhu J, Fukushige T, McGhee JD, Rothman JH. Reprogramming of early embryonic blastomeres into endodermal progenitors by a Caenorhabditis elegans GATA factor. Genes Dev. 1998;12:3809-14.

88. Maduro MF, Rothman JH. Making worm guts: the gene regulatory network of the Caenorhabditis elegans endoderm. Dev Biol. 2002;246:68-85.

89. Rocheleau CE, Downs WD, Lin R, Wittmann C, Bei Y, Cha YH, et al. Wnt signaling and an APC-related gene specify endoderm in early C. elegans embryos. Cell. 1997:90:707-16.

90. Mizumoto K, Sawa H. Two betas or not two betas: regulation of asymmetric division by beta-catenin. Trends Cell Biol. 2007;17:465-73.

91. Azzaria M, Goszczynski B, Chung MA, Kalb JM, McGhee JD. A fork head/ HNF-3 homolog expressed in the pharynx and intestine of the Caenorhabditis elegans embryo. Dev Biol. 1996;178:289-303.

92. Horner MA, Quintin S, Domeier ME, Kimble J, Labouesse M, Mango SE. pha-4, an HNF-3 homolog, specifies pharyngeal organ identity in Caenorhabditis elegans. Genes Dev. 1998;12:1947-52.

93. Kalb JM, Lau KK, Goszczynski B, Fukushige T, Moons D, Okkema PG, et al. pha-4 is Ce-fkh-1, a fork head/HNF-3alpha, beta, gamma homolog that functions in organogenesis of the C. elegans pharynx. Development. 1998;125:2171-80.

94. Harfe $B D$, Fire A. Muscle and nerve-specific regulation of a novel NK-2 class homeodomain factor in Caenorhabditis elegans. Development. 1998:125:421-9.

95. Satterlee JS, Sasakura H, Kuhara A, Berkeley M, Mori I, Sengupta P. Specification of thermosensory neuron fate in C. elegans requires $t$ tx-1, a homolog of otd/Otx. Neuron. 2001;31:943-56.

96. Lanjuin A, VanHoven MK, Bargmann Cl, Thompson JK, Sengupta P. Otx/otd homeobox genes specify distinct sensory neuron identities in C. elegans. Dev Cell. 2003:5:621-33.

97. Robinson-Rechavi M, Maina CV, Gissendanner CR, Laudet V, Sluder A Explosive lineage-specific expansion of the orphan nuclear receptor HNF4 in nematodes. J Mol Evol. 2005;60:577-86.

98. Miyabayashi T, Palfreyman MT, Sluder AE, Slack F, Sengupta P. Expression and function of members of a divergent nuclear receptor family in Caenorhabditis elegans. Dev Biol. 1999;215:314-31.

99. Pocock R, Ahringer J, Mitsch M, Maxwell S, Woollard A. A regulatory network of T-box genes and the even-skipped homologue vab-7 controls patterning and morphogenesis in C. elegans. Development. 2004;131:2373-85.

100. Edgar LG, Carr S, Wang H, Wood WB. Zygotic expression of the caudal homolog pal-1 is required for posterior patterning in Caenorhabditis elegans embryogenesis. Dev Biol. 2001;229:71-88.

101. Jackson BM, Eisenmann DM. beta-catenin-dependent Wnt signaling in C. elegans: teaching an old dog a new trick. Cold Spring Harb Perspect Biol. 2012:4:a007948.

102. Bronner G, Chu-LaGraff Q, Doe CQ, Cohen B, Weigel D, Taubert H, et al. Sp1/egr-like zinc-finger protein required for endoderm specification and germ-layer formation in Drosophila. Nature. 1994;369:664-8.

103. Weisbrod A, Cohen M, Chipman AD. Evolution of the insect terminal patterning system - insights from the milkweed bug, Oncopeltus fasciatus Dev Biol. 2013;380:125-31.

104. Duncan EJ, Benton MA, Dearden PK. Canonical terminal patterning is an evolutionary novelty. Dev Biol. 2013;377:245-61.

105. Zhong W, Sladek FM, Darnell Jr JE. The expression pattern of a Drosophila homolog to the mouse transcription factor HNF-4 suggests a determinative role in gut formation. EMBO J. 1993;12:537-44.

106. Weigel $D$, Jürgens $G$, Kuttner F, Seifert $E$, Jäckle $H$. The homeotic gene fork head encodes a nuclear protein and is expressed in the terminal regions of the Drosophila embryo. Cell. 1989;57:645-58. 
107. Campbell K, Whissell G, Franch-Marro X, Batlle E, Casanova J. Specific GATA factors act as conserved inducers of an endodermal-EMT. Dev Cell. 2011;21:1051-61.

108. Finkelstein R, Perrimon N. The orthodenticle gene is regulated by bicoid and torso and specifies Drosophila head development. Nature. 1990;346:485-8.

109. Zaffran S, Das G, Frasch M. The NK-2 homeobox gene scarecrow (scro) is expressed in pharynx, ventral nerve cord and brain of Drosophila embryos. Mech Dev. 2000;94:237-41.

110. Goriely A, Stella M, Coffinier C, Kessler D, Mailhos C, Dessain S, et al. A functional homologue of goosecoid in Drosophila. Development 1996;122:1641-50.

111. Kispert A, Herrmann BG, Leptin M, Reuter R. Homologs of the mouse Brachyury gene are involved in the specification of posterior terminal structures in Drosophila, Tribolium, and Locusta. Genes Dev. 1994:8:2137-50.

112. Patel $\mathrm{NH}$, Ball EE, Goodman CS. Changing role of even-skipped during the evolution of insect pattern formation. Nature. 1992;357:339-42.

113. Wu LH, Lengyel JA. Role of caudal in hindgut specification and gastrulation suggests homology between Drosophila amnioproctodeal invagination and vertebrate blastopore. Development. 1998;125:2433-42.

114. Vorwald-Denholtz PP, De Robertis EM. Temporal pattern of the posterior expression of Wingless in Drosophila blastoderm. Gene Expr Patterns. 2011;11:456-63.

115. Telford MJ, Bourlat SJ, Economou A, Papillon D, Rota-Stabelli O. The evolution of the Ecdysozoa. Philos Trans R Soc Lond B Biol Sci. 2008;363:1529-37.

116. Schmidt-Rhaesa A, Bartolomaeus T, Lemburg C, Ehlers U, Garey JR. The position of the Arthropoda in the phylogenetic system. J Morph. 1998;238:263-85.

117. Stein LD, Bao Z, Blasiar D, Blumenthal T, Brent MR, Chen N, et al. The genome sequence of Caenorhabditis briggsae: a platform for comparative genomics. PLoS Biol. 2003;1, E45.

118. Pascual-Anaya J, Albuixech-Crespo B, Somorjai IM, Carmona R, Oisi Y, Alvarez $\mathrm{S}$, et al. The evolutionary origins of chordate hematopoiesis and vertebrate endothelia. Dev Biol. 2013;375:182-92.

119. Shimeld SM. Characterisation of amphioxus HNF-3 genes: conserved expression in the notochord and floor plate. Dev Biol. 1997;183:74-85.

120. Venkatesh TV, Holland ND, Holland LZ, Su MT, Bodmer R. Sequence and developmental expression of amphioxus AmphiNk2-1: insights into the evolutionary origin of the vertebrate thyroid gland and forebrain. Dev Genes Evol. 1999;209:254-9.

121. Brooke NM, Garcia-Fernandez J, Holland PWH. The ParaHox gene cluster is an evolutionary sister of the Hox gene cluster. Nature. 1998;392:920-2.

122. Boyle MJ, Seaver EC. Developmental expression of foxA and gata genes during gut formation in the polychaete annelid Capitella sp. I Evol Dev. 2008;10:89-105.

123. Boyle MJ, Yamaguchi E, Seaver EC. Molecular conservation of metazoan gut formation: evidence from expression of endomesoderm genes in Capitella teleta (Annelida). EvoDevo. 2014;5:39.

124. Fröbius AC, Seaver EC. ParaHox gene expression in the polychaete annelid Capitella sp. I Dev Genes Evol. 2006;216:81-8.

125. Seaver EC, Kaneshige LM. Expression of 'segmentation' genes during larval and juvenile development in the polychaetes Capitella sp, I and $\mathrm{H}$. elegans. Dev Biol. 2006;289:179-94.

126. Hejnol A, Martindale MQ. Acoel development indicates the independent evolution of the bilaterian mouth and anus. Nature. 2008:456:382-6.

127. Martín-Durán JM, Romero R. Evolutionary implications of morphogenesis and molecular patterning of the blind gut in the planarian Schmidtea polychroa. Dev Biol. 2011;352:164-76.

128. Annunziata R, Perillo M, Andrikou C, Cole AG, Martinez P, Arnone MI. Pattern and process during sea urchin gut morphogenesis: the regulatory landscape. Genesis. 2014:52:251-68.

129. McGhee JD, Sleumer MC, Bilenky M, Wong K, McKay SJ, Goszczynski B, et al. The ELT-2 GATA-factor and the global regulation of transcription in the $C$. elegans intestine. Dev Biol. 2007:302:627-45.
130. Sommermann EM, Strohmaier KR, Maduro MF, Rothman JH. Endoderm development in Caenorhabditis elegans: the synergistic action of ELT-2 and -7 mediates the specification $\rightarrow$ differentiation transition. Dev Biol. 2010;347:154-66.

131. Katoh K, Standley DM. MAFFT multiple sequence alignment software version 7: improvements in performance and usability. Mol Biol Evol. 2013;30:772-80.

132. Castresana J. Selection of conserved blocks from multiple alignments for their use in phylogenetic analysis. Mol Biol Evol. 2000;17:540-52.

133. Stamatakis A. RAxML version 8: a tool for phylogenetic analysis and post-analysis of large phylogenies. Bioinformatics. 2014;30:1312-3.

\section{Submit your next manuscript to BioMed Central and take full advantage of:}

- Convenient online submission

- Thorough peer review

- No space constraints or color figure charges

- Immediate publication on acceptance

- Inclusion in PubMed, CAS, Scopus and Google Scholar

- Research which is freely available for redistribution 